$$
\text { ص ص[Mrq- r.qu }
$$

$$
\begin{aligned}
& \text { الأزمات المالية العالمية } \\
& \text { قياس ومحاكاة لأزمات مالية في بلدان عربية مختارة } \\
& \text { الدكورة سراء سالم داؤد }
\end{aligned}
$$

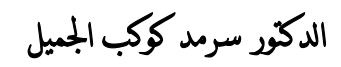

$$
\begin{aligned}
& \text { مدرس - قسم العلوم المالية والمصرفية } \\
& \text { أستاذ مساعد - قسم العلوم المالية والمصرفية } \\
& \text { كلية الإدارة والاقصطاد -جامعة الموصل }
\end{aligned}
$$

Sarmad_aljamil53@yahoo.com

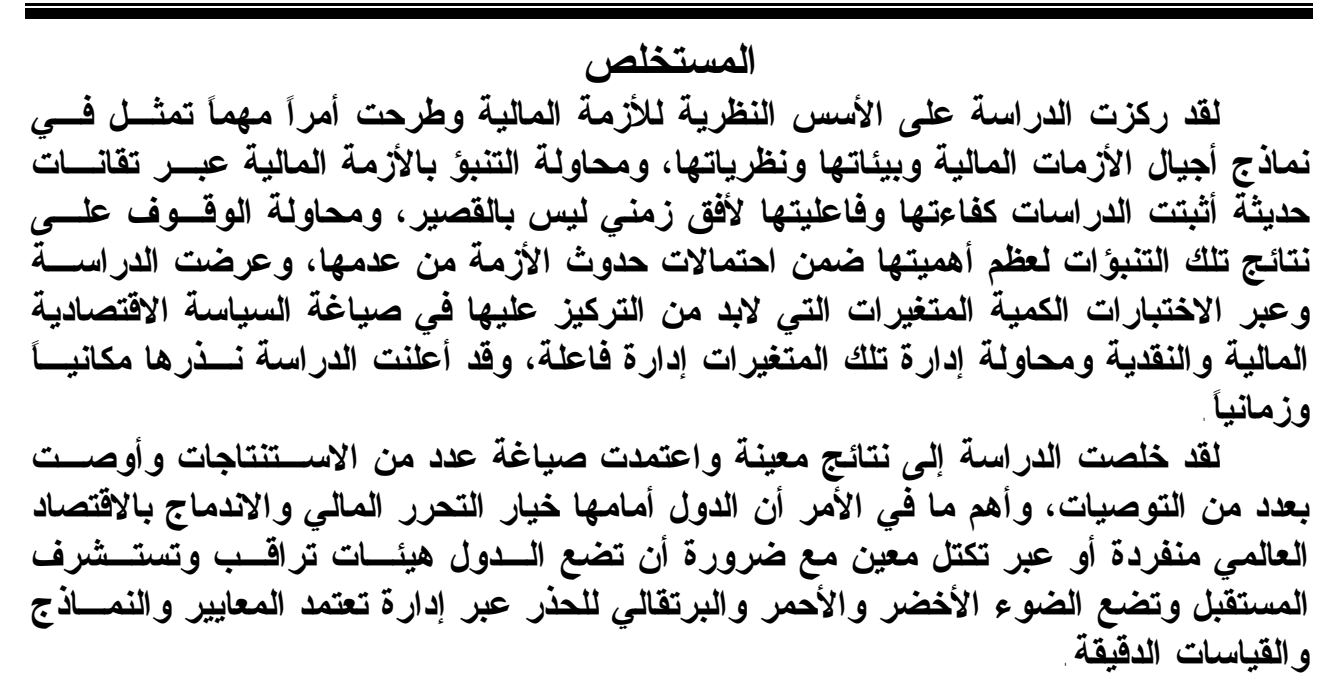

\title{
International Financial Crises Measurement and Simulation of Financial Crises in Selected Arab Countries
}

\author{
Sarmad K. Al-Jameel (PhD) \\ Assistant Professor \\ Sarra S. Dawood(PhD) \\ Department of Financial and Banking Sciences \\ Lecturer \\ University of Mosul
}

\section{Abstract}

The present study concentrates on the theoretical bases of financial crises. It reflects samples of generation of financial crises, their environment and theories. The present study goes through all variables that must be concentrated on informing the monetary, economic

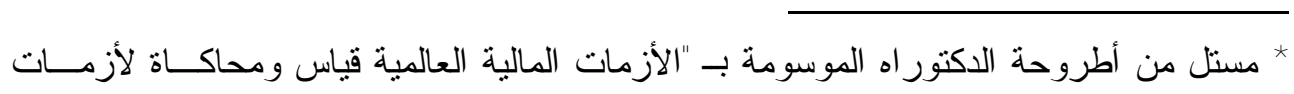

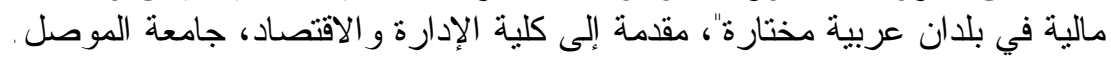

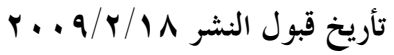

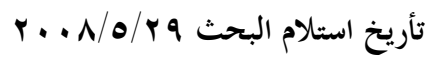




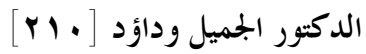

and financial policies and trying the administration of these variables. This study ended with certain results, reached some conclusions and presented some recommendations. The most important thing is that the countries have the choice of financial liberation and integration in world economy either individually or through certain groups or communities, some committees must be formed in order to observe the activities and to read the future and put green, red and yellow colors for precaution through the administration depending on precise criteria, models and standards.

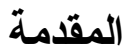

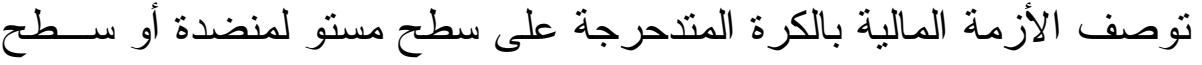

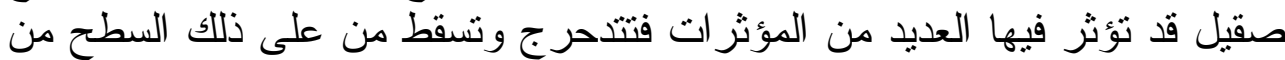

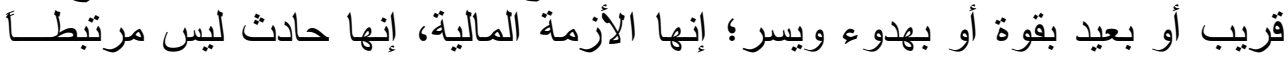

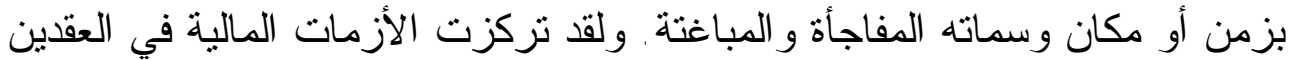

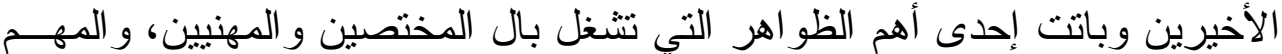
في توصيف الظاهرة البحثية يتمنل في مظاهر ها وهي كما يأتي : الانخفاض الكبير وانير و المفاجئ في قيمة العملة، و انهيار النظامين المصرفي و المالي، وتعطل عمل آليات

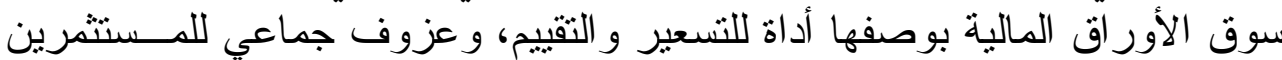

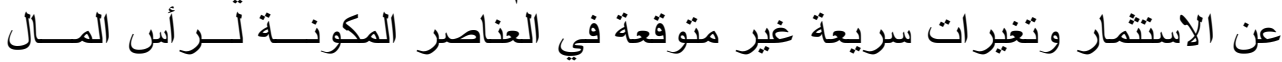

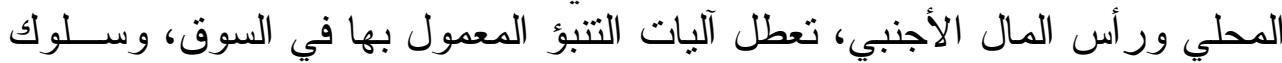

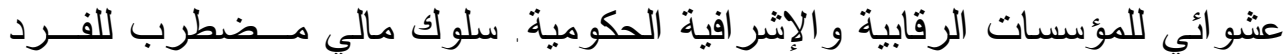

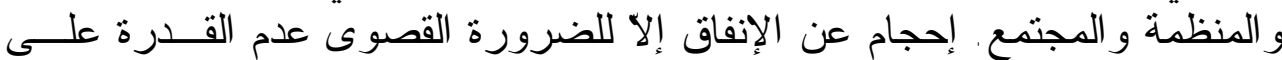

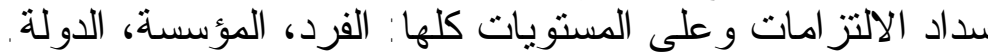

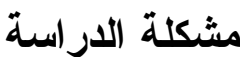
تبرز مشكلة البحث و اضحة وجلية عبر عدة تساؤلات و وأبعاد :

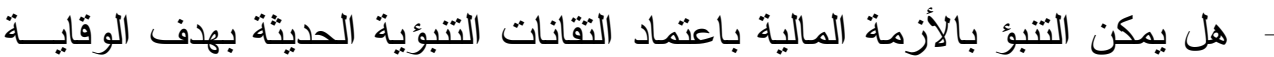
منها!

- - هل بمكن رسم أنماط معينة عبر قو اسم مشتركة بين الأزمات المالية؟

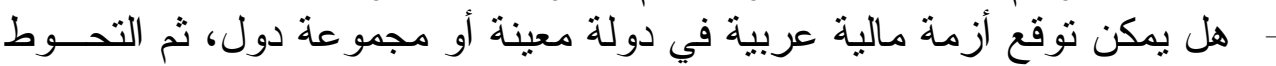
لهاب - هل بمكن معرفة أي من المتغير ات الاقتصادية التي تـسبب وقــوع الأزمــات

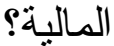

\section{أهمبة الار اسة}

لقد بدأ هاجس الأزمة المالية يؤرق حكومات العديد من الــدول و المنظمــات الدولية و المؤسسات المالية على الرغم مما برز من تحالفات وشر اكات و واتفاقيــات

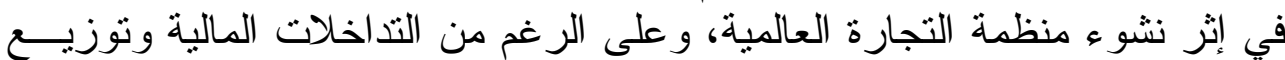
المنافع و الكلف . و الأهم من ذللك أن هذا الموضوع وعلى على الرغم من ســعة انتـشاره 


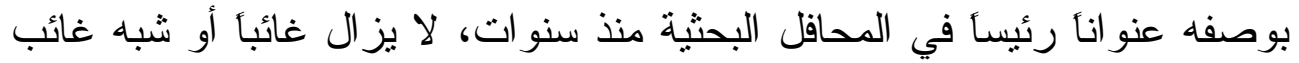

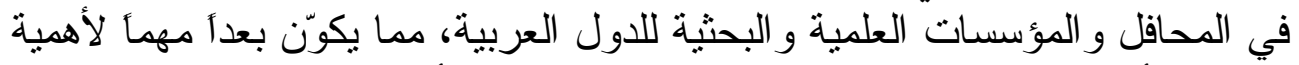
در اسة الأزمات المالية وقياس ظاهرتها والئه والتعرف على أبعادها.

$$
\text { أهداف الدراسة الدر اسة إلى: }
$$

ا ـ تأطير الأسس النظرية لمفاهيم الأزمات المالية.

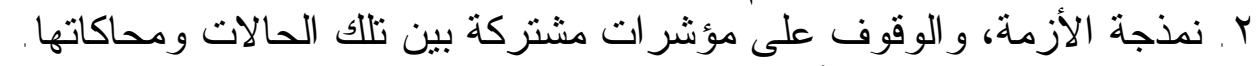

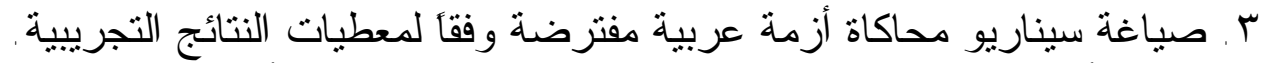
ع ـ معرفة أي المتغير ات الاقتصادية الكلية المؤثز في حصول الأزمة.

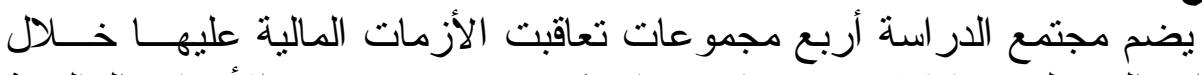

\section{مجتمع الدراسة}

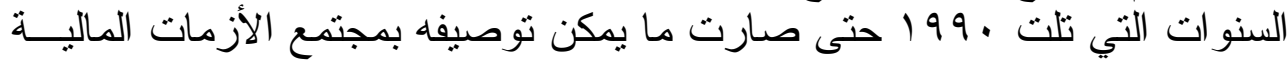

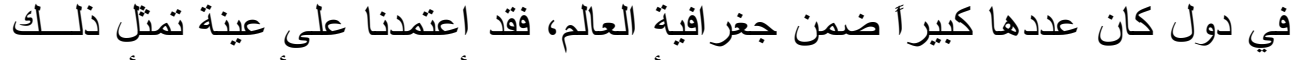

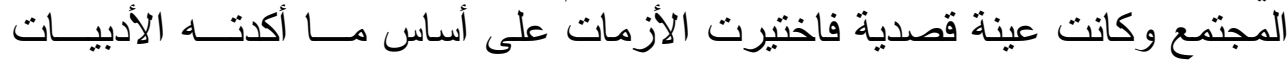

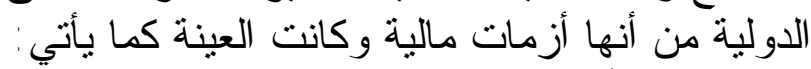

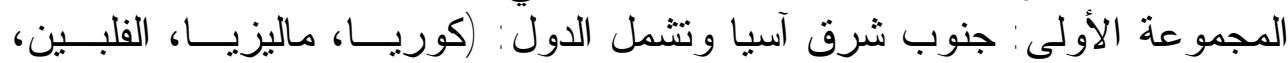

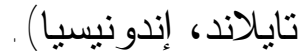

المجموعة الثانية: أمريكا اللاتينية وتشمل الدونيان الدول (الأرجنتين، البرازيل، المكسيك، شيلي، الإكو ادور ).

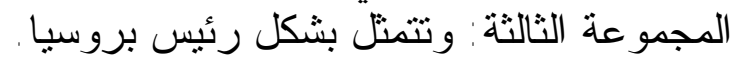
المجمو عة الر ابعة: وتتمثنل بشكل رئيس بترئ بتركيا.

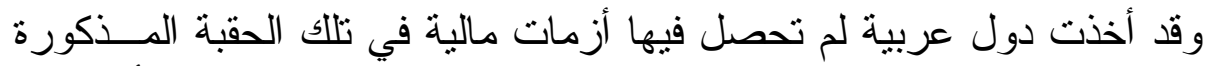

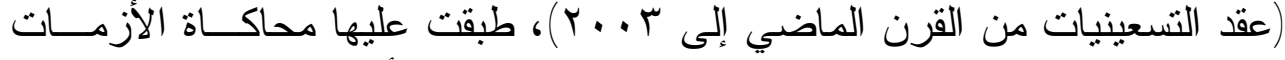

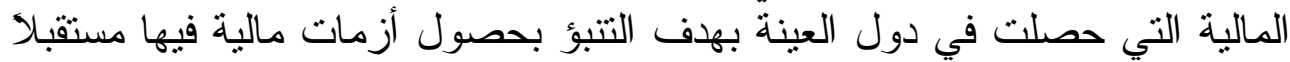
(السعودية، الكويت، البحرين، الإمار في دات).

اعتمد عدد من الفرضيات للوصول إلى هدف الدراسة الته وهي كما يأتي:

$$
\text { فرضيات الاراسة }
$$

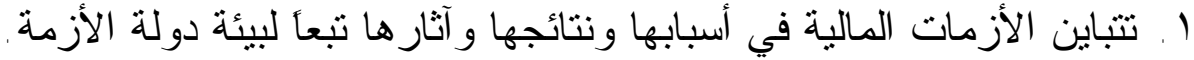

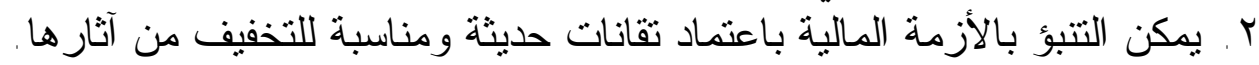

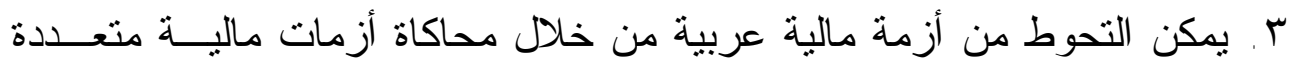

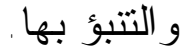




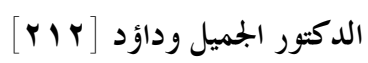

ع. . يوجد عدد من المتغير ات الاقتصادية الكلية التي تؤثر مباثــرة فـي إحـــاث

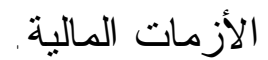

أولاً - مفاهيم الأزمات المالية و أسبابها

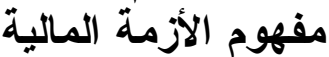

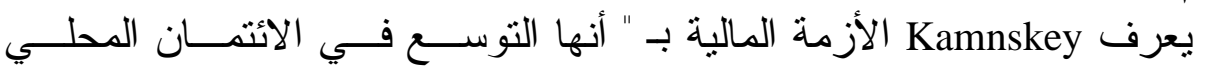

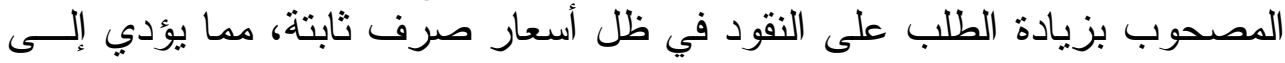

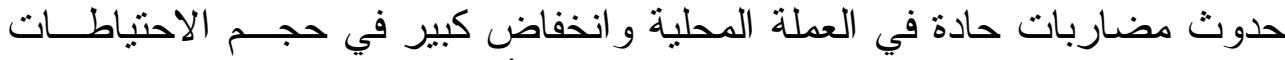

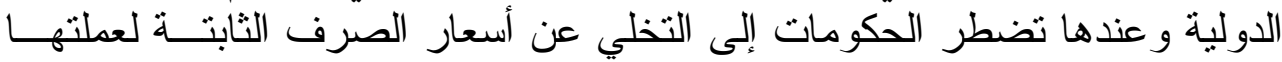

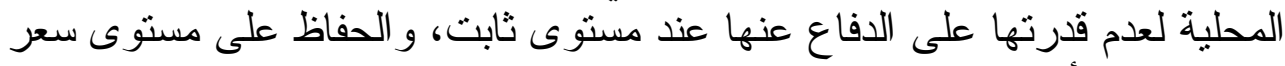

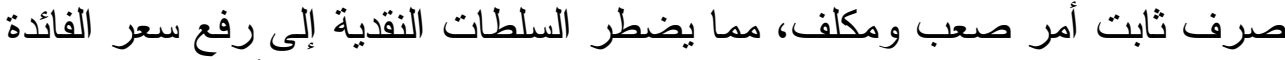

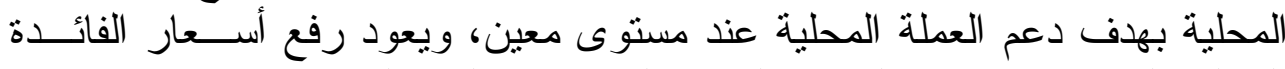

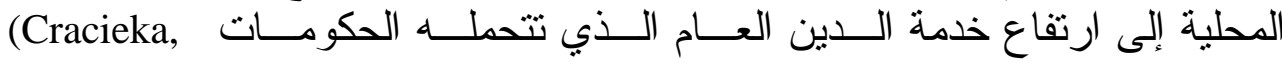

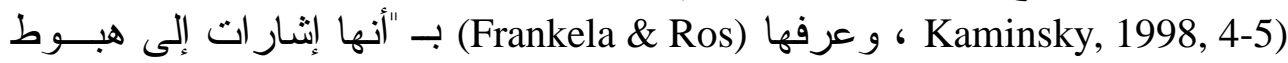

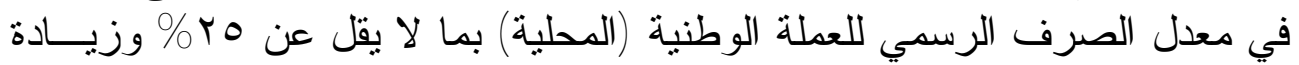

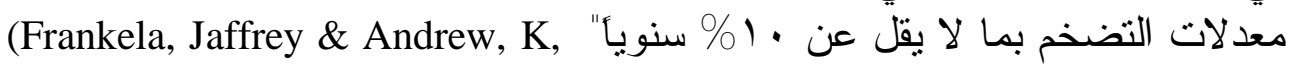

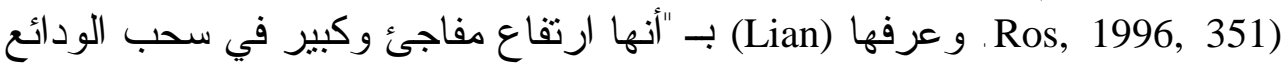

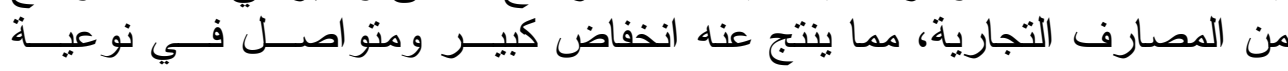

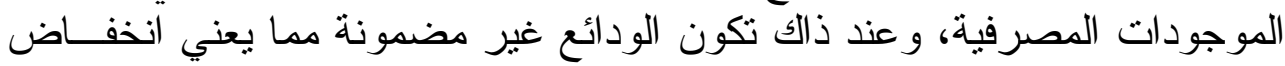

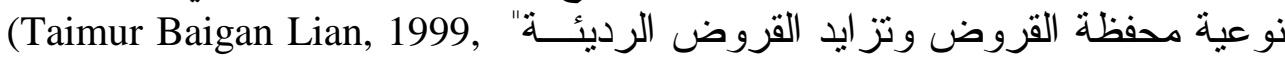

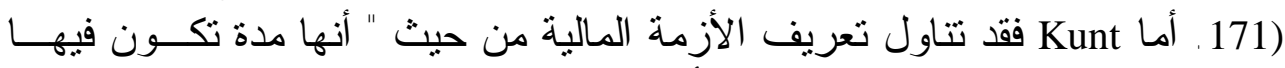

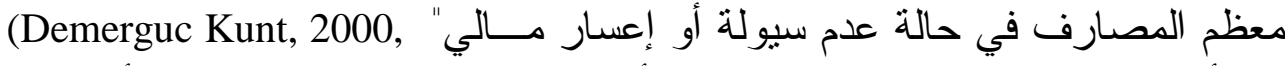

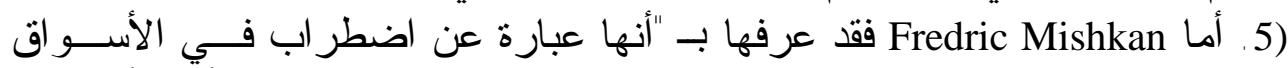

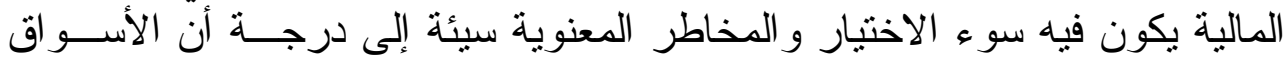

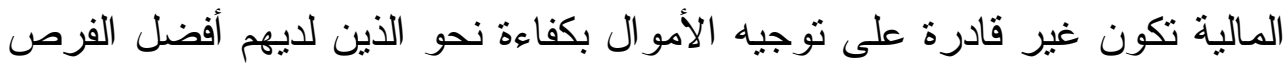

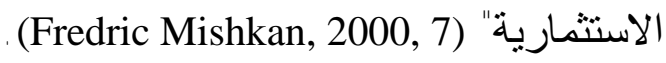

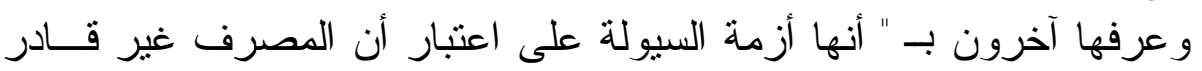

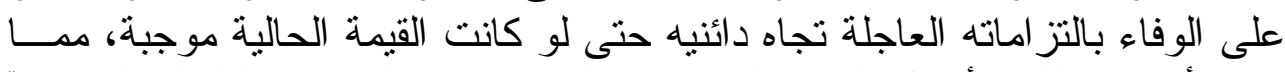

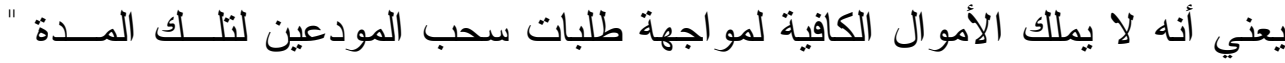
.(Manmohan S. Kumar, 2001)

\section{تطور أجيال الأزمات المالية}

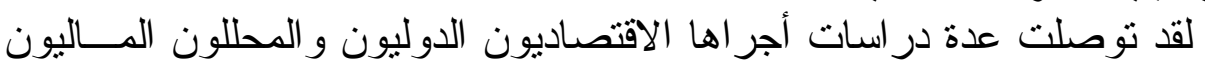

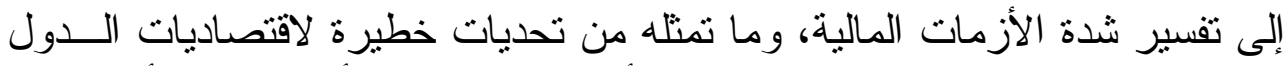

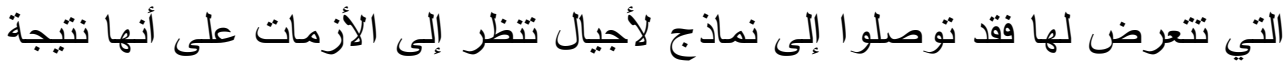




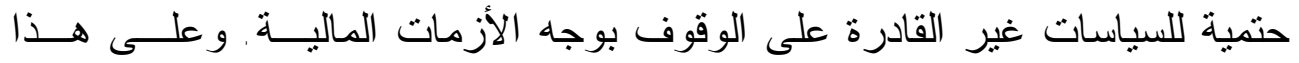

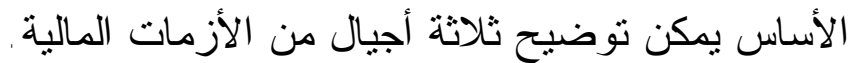

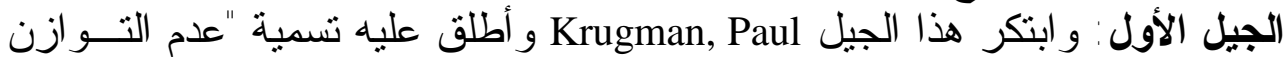

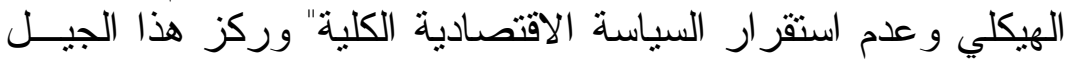
على نظام سعر الصرف الذي يمنل أحد المكونات الأساسية للاقتصاد الكلي، (Paolo Pesenti and Cedric Tille, 2000, 5-7).

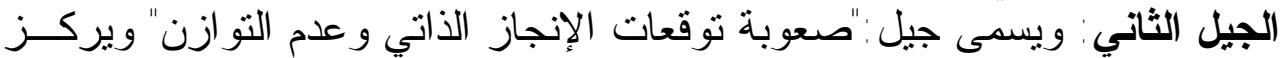

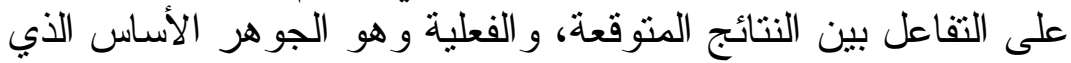

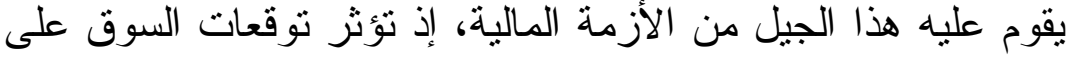

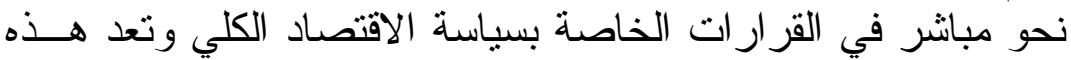

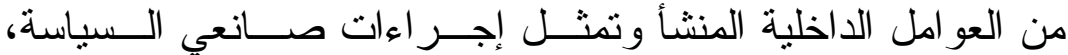
.(Stephen Grenville, 1998)

الجيل الثالث: ابتكر هذا الجيل Pyo, Hak ويعد جيلا جديداً من نظريــة الأزمــات

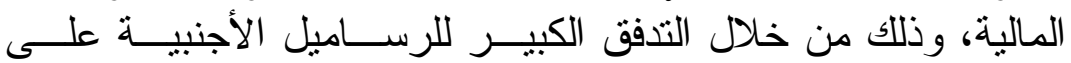

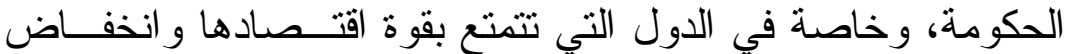

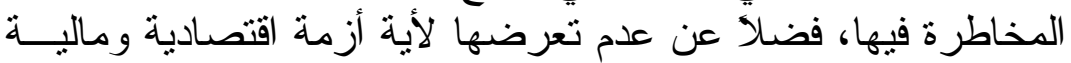
سابقا (Pyo, Hak, K. 2002).

و أسباب الأزمات المالية 1. الأسباب الاقتصادية: إن عدم الاستقر ار في المتغير ات الاقتـــــادية و التقلبــات

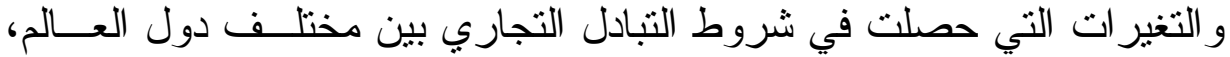

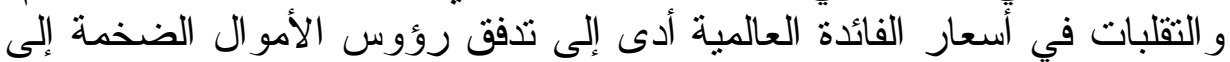
(Mariassunta, Gionnetti, 2004, و الــدول الناميــة (IMF, Survey, 1998, 2)

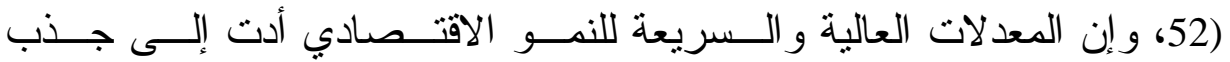

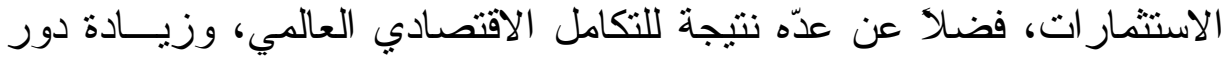

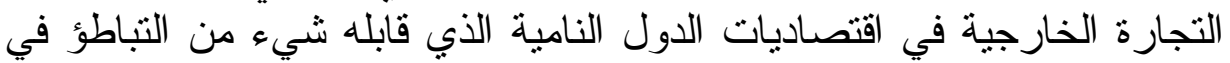

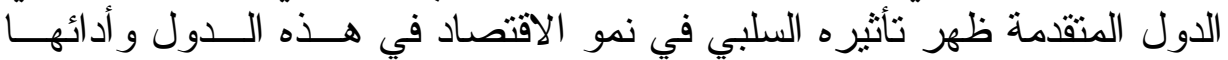

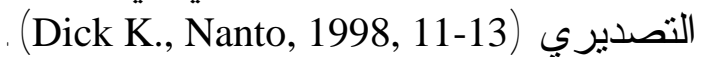

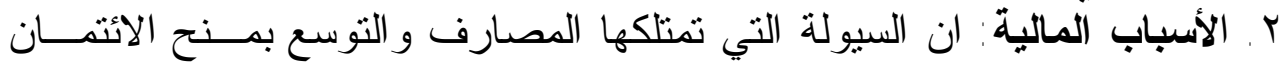

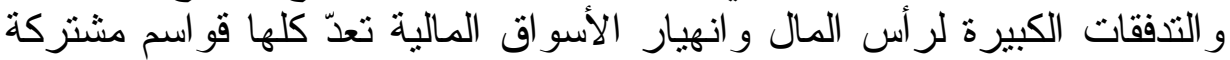

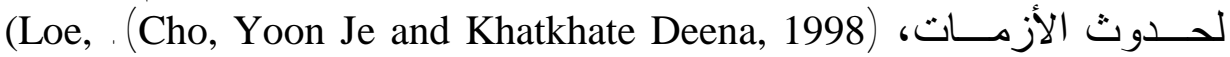
(Chung, H., Lee, 2004, ،(Dick, K., Nanto, 1998, 15) ،Jangsoo, 1991) (Chung, H., Lee, 2004, 8-11) وقد قام البنك الدولي بدر اسة خاصة لإيجاد 


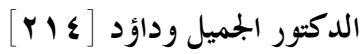

العلاقة بين الكفاءة و القيام بتحديد الموارد وتوصل إلى أن الإصلاح المالي هو

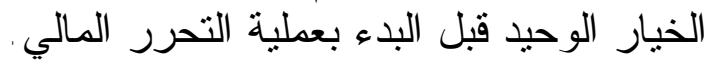

r. أسباب ثقة (نفسية): إن بروز بعلية أزمة الثقة التني سبيها التدفق الكبير لر أس المال

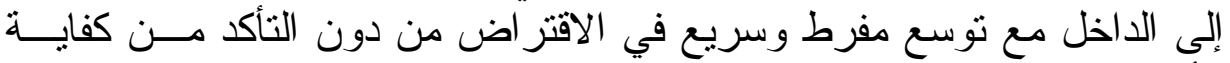

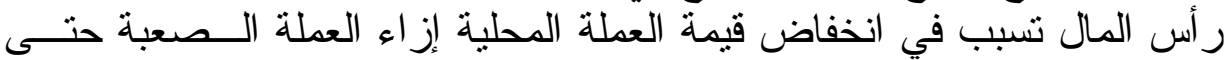

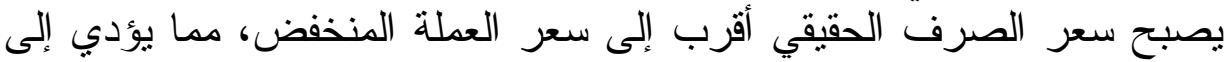

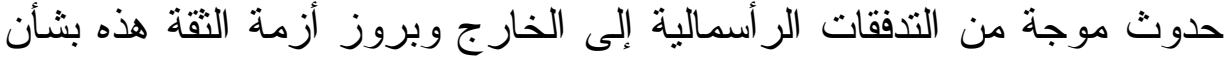

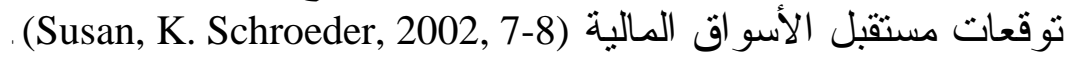

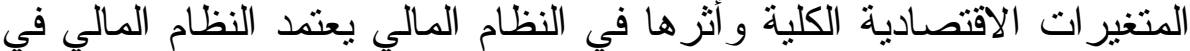

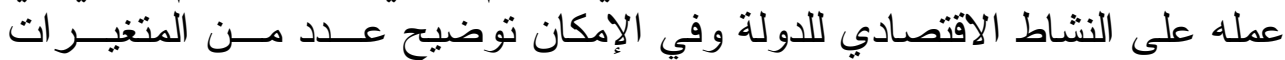

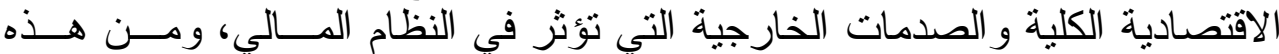

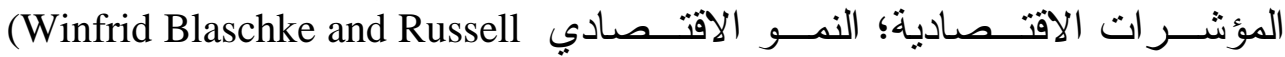

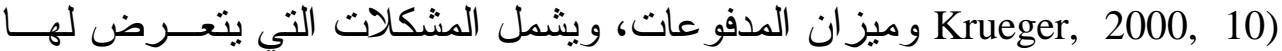
ميز ان الدفو عات وتتمثل في الآتـي: (Winfrid Blaschke and Russell Krueger) (2000, 11-12 عجز الحساب الجاري، و وانخفاض الإحتياطي وزيادة الدين الأجنبي،

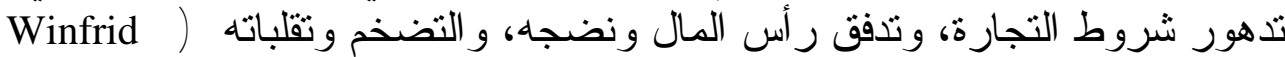
وBlaschke and Russell Krueger, 2000, 14

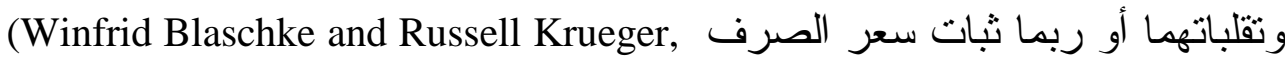
(Winfrid Blaschke and 2000, 15) .Russell Krueger, 2000, 16)

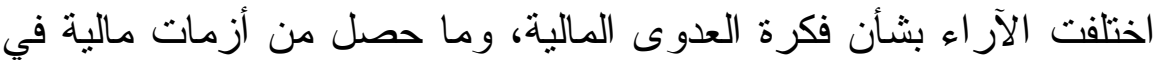

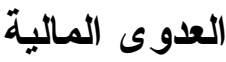

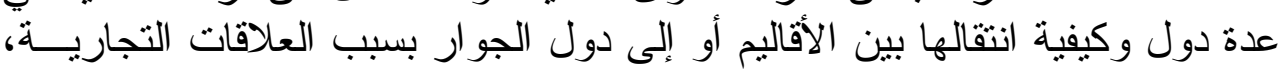

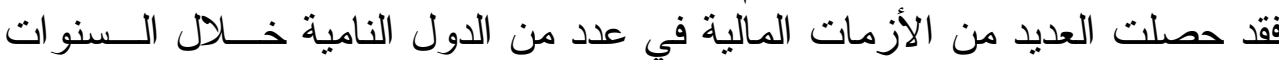

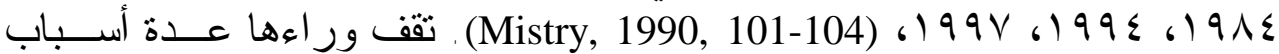

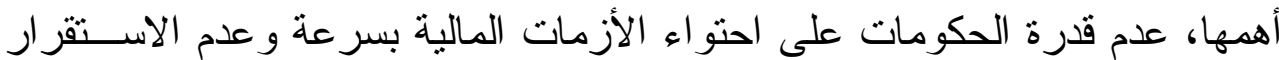

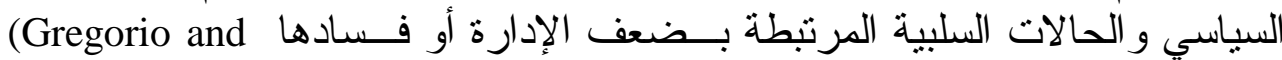
‘(Bordo and Eichengreen, 1999, 19-22) Valdes, 2001, 289-301) (Dasgupta, 2004, 5) ( وتتتقل الأزمة المالية من الدولة المصابة إلى الدولة الأخرى (B.

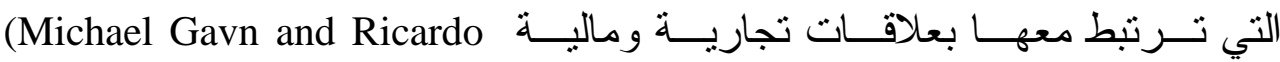
.Hausemann, 1999, 4-5)

عقلانية الاستجابة لو اقعية الدولرة

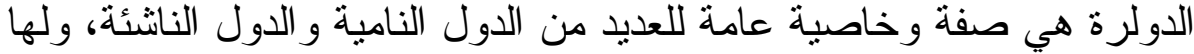
مضامين مهمة للاستقر ار المالي فهي مفيدة للاستقر ارية المالية و التطور المالي في الني 


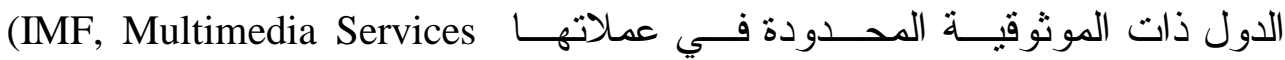
.(Jacome, 2004, 33) ‘Division, 2004, 1-2)

\section{منهجية البحث وبياناته}

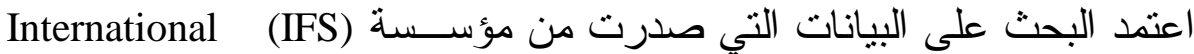

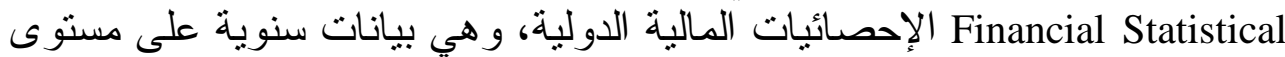

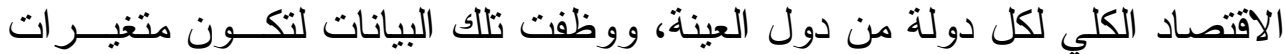

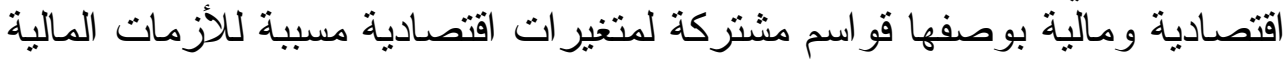

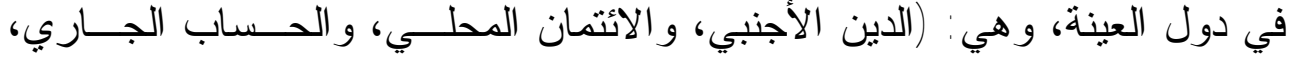

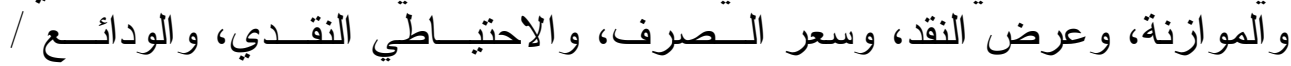

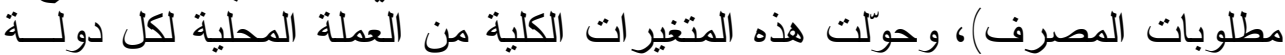

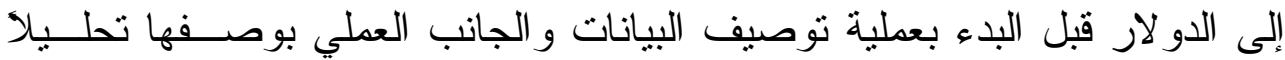
إحصائياً و أسلوبأ للتنبؤ، فضلاء عن المحاكاة و الانحدار الخطي المتعدد.

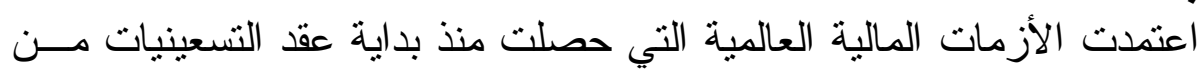

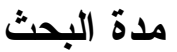

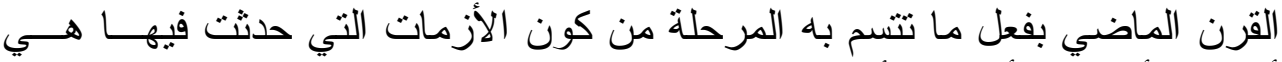

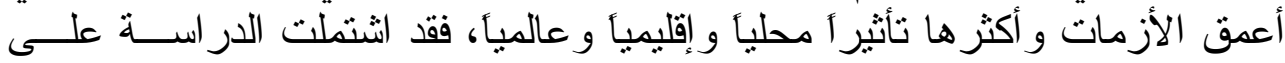

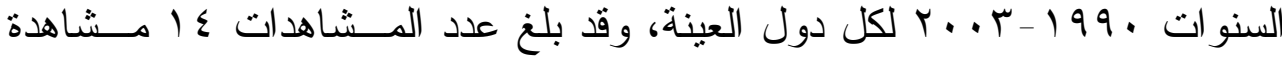

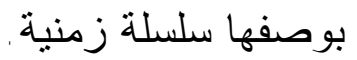

بهدف اختبار الفرضيات البحثية اعتمد على مجموعة من الأدوات الإحصائية

$$
\text { أدوات البحث }
$$
التي يمكن تقسيمها على أدوات توصيف البيانات، و أدوات التحليل ونيل واختبار ها، وكما لأليا يأتي : أدوات توصيف البيانات الوسط الحسابي المتوسط و الانحر اف المعياري و أعلى و أدنى قيمة ومعامــلـ لوسل الالنو اءو التقلطح.

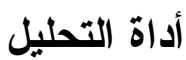

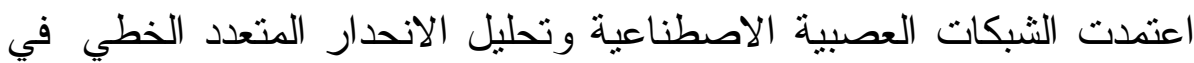

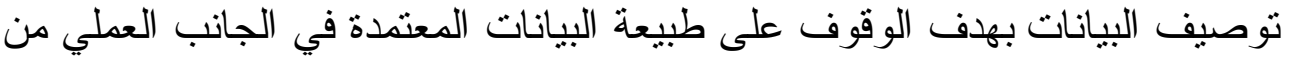

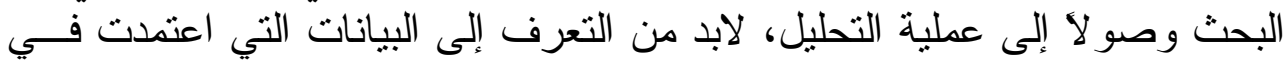

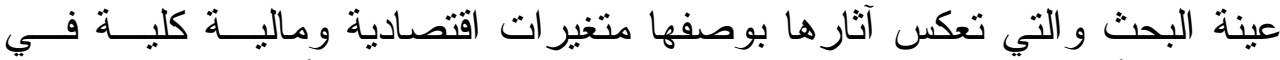
حصول الأزمات "المالية لدول العينة، وتبين من معامل التفلطح أن دول العينة لعينة جميعاً 


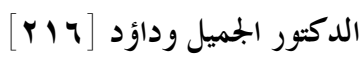

تقع ضمن التوزيع الطبيعي خلال المدة المذكورة ماعدا دولة روسيا فثمة مسستوى تذبذب بسيط في قيم المتغير ات.

مناقثة نتائج تطبيق استخدام الثبكات العصبية للتنبؤ بالأزمات المالية ومحاكاتها أظهرت نتائج تطبيق الثبكات العصبية العبية ما يأتي:

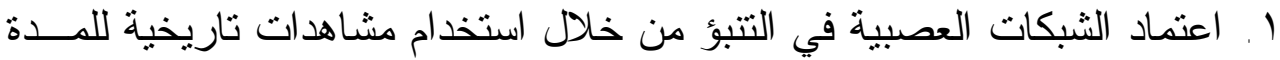

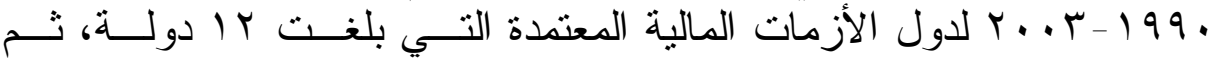

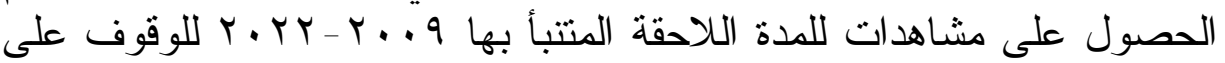
أزمة مالية متتبأ بها.

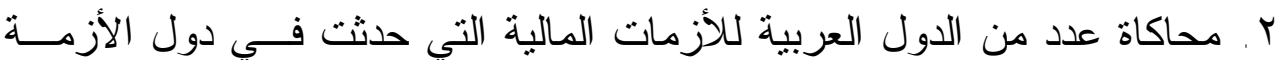

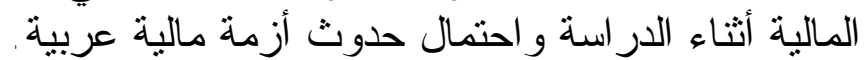

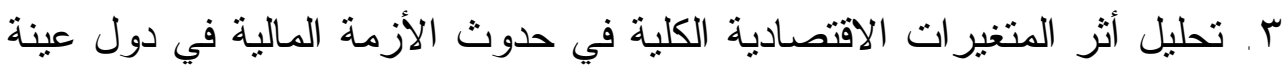

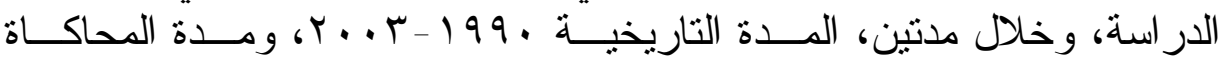


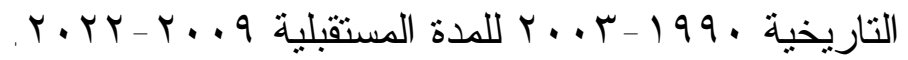

استخدام الثبكات العصبية في التتبؤ بأزمة مالية في دول الأزمات المالية

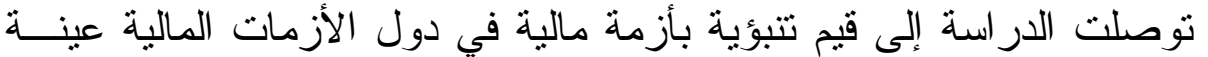

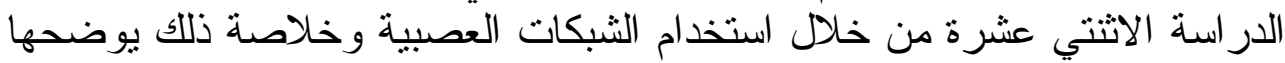

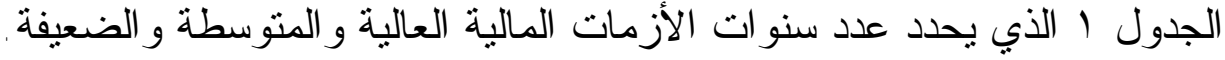

\begin{tabular}{|c|c|c|}
\hline \multicolumn{3}{|c|}{ مؤشرات احتمالية وقوع الأزمة المالية أو } \\
\hline 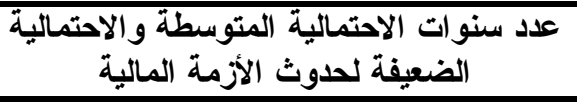 & علد سنوات الاحتمالية العالية & دول الأزمة المالية \\
\hline $1 \pi$ & 1 & المكسيك \\
\hline $1 \pi$ & 1 & البر ازيل \\
\hline 1. & $\varepsilon$ & الإكو ادور \\
\hline$\Lambda$ & 7 & تيلي \\
\hline $1 \varepsilon$ & -- & الأرجنتين \\
\hline 11 & $r$ & تايلاند \\
\hline$v$ & v & كوريا \\
\hline 9 & 0 & إندونيسيا \\
\hline 0 & 9 & الفلبين \\
\hline 7 & $\wedge$ & ماليزيا \\
\hline
\end{tabular}




\begin{tabular}{|c|c|c|}
\hline عدد سنوات الاحتمالية المتوسطة والإحتمالية المالية & عداد سنوات الأزمتمالية العالية & دول الأزمة المالية \\
\hline V & v & تركيا \\
\hline $1 \varepsilon$ & -- & روسيا \\
\hline
\end{tabular}

المصدر: من إعداد الباحثين.

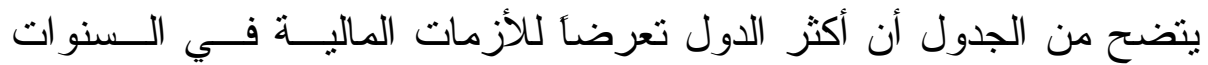

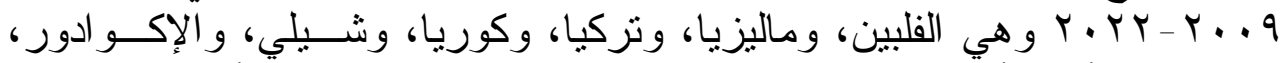

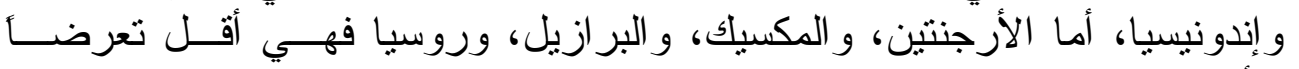

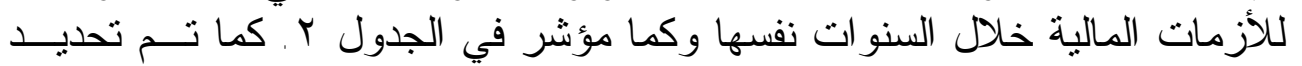
سنو ات تللك الأزمات بحسب الدول النين التي تظهر في الجدول.

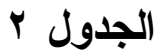

مؤشرات الاحتمالية العالية لوقوع الأزمة المالية في دول الأزمة المالية

\begin{tabular}{|c|c|c|c|c|c|c|c|c|c|c|c|c|c|c|}
\hline i & I & ! & ב & $\dot{z}$ & $\dot{z}$ & 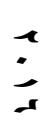 & 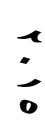 & $\dot{m}$ & ! & i & 三 & ! & : & الدولة \\
\hline & & & & & & & & & & $x$ & & & & المكسيك \\
\hline & & & & & & & & & $x$ & & & & & البر ازيل \\
\hline & $x$ & & & & & & & & $x$ & $x$ & $x$ & & & الإكو ادور \\
\hline$x$ & $x$ & & & & & & $x$ & & & $x$ & & $x$ & $x$ & شيلي \\
\hline & & & & & & & & & & & & & & الأرجنتين \\
\hline & & & & & & & & $x$ & & $x$ & & & $x$ & تايلاند \\
\hline & & $x$ & & $x$ & $x$ & $x$ & $x$ & & & $x$ & $x$ & & & كوريا \\
\hline & & & & & $x$ & & & $x$ & $x$ & $x$ & $x$ & & & إندو نيسيا \\
\hline & & & & $x$ & $\bar{x}$ & $x$ & $x$ & $x$ & & $x$ & $x$ & $\bar{x}$ & $x$ & الفيليبين \\
\hline$x$ & & $x$ & $x$ & & $x$ & & & & $x$ & & $x$ & $x$ & $x$ & ماليزيا \\
\hline & $x$ & $x$ & $x$ & $x$ & & & & & & $x$ & & $x$ & $x$ & زركيا \\
\hline & & & & & & & & & & & & & & روسيا \\
\hline
\end{tabular}

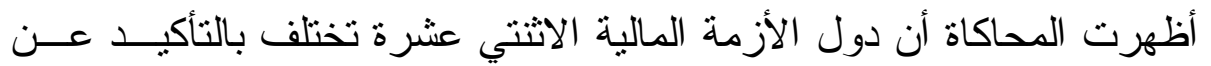

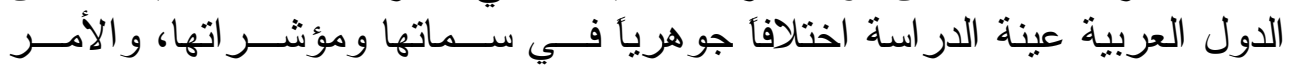

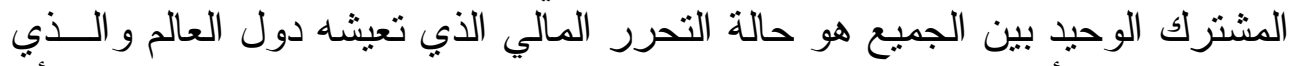

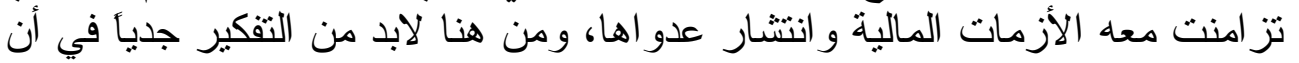

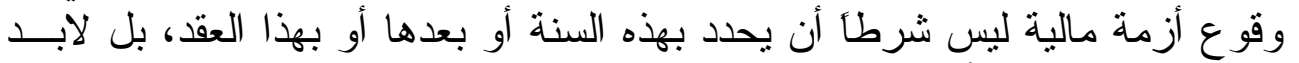

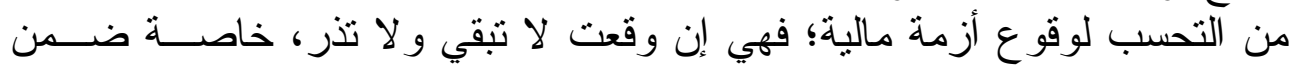

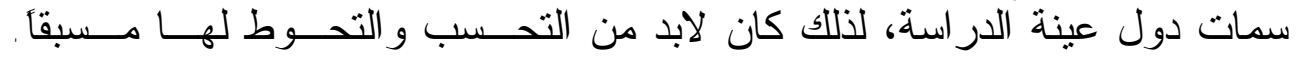




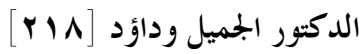

والاستتناج الذي يمكن أن نقف عنده، هو أن محاكاة كل دولة عربية مــن الــدول

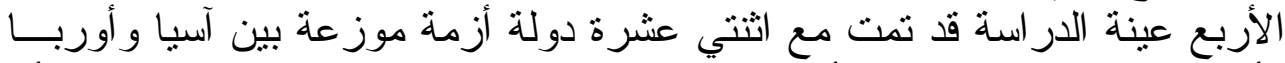

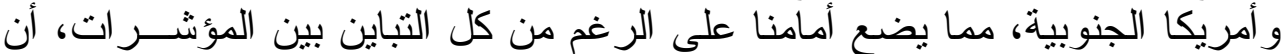

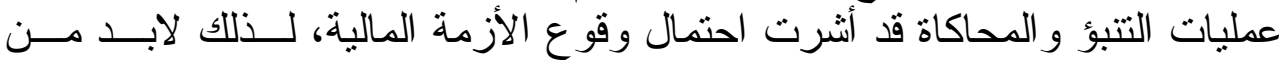
حصر مضامين التحليل ومفاده.

\begin{tabular}{|c|c|c|c|c|c|c|c|c|}
\hline \multicolumn{9}{|c|}{ 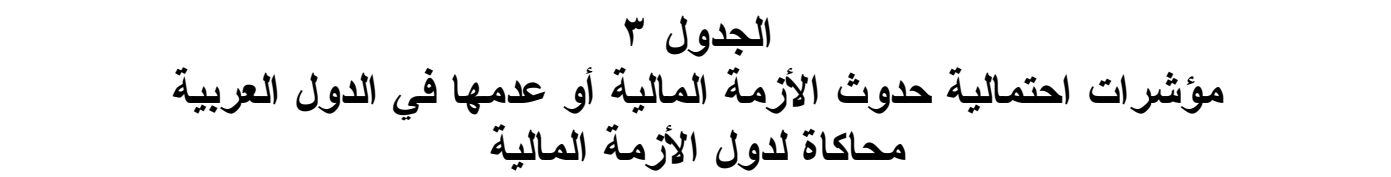 } \\
\hline \multicolumn{2}{|c|}{ البحرين } & \multicolumn{2}{|c|}{ الكويت } & \multicolumn{2}{|c|}{ الإمارات } & \multicolumn{2}{|c|}{ المملكة العربية السعودية } & \multirow[b]{2}{*}{ دول الأزمة } \\
\hline سنواتل & سنواتية & سنواتل & سنواتل الاحتمالية & 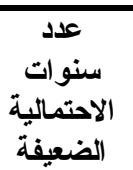 & سلاحتواتية & الاحتمالية & عدد سنوات الاحتمالية & \\
\hline $1 \varepsilon$ & $-\cdot$ & $1 \varepsilon$ & -- & $1 \varepsilon$ & $-\cdot$ & $1 \varepsilon$ & $\overline{-}$ & المكسيك \\
\hline $1 \varepsilon$ & $-\cdot$ & 14 & 1 & $1 \varepsilon$ & -- & $\Lambda$ & 7 & البر ازيل \\
\hline 0 & 9 & $1 \varepsilon$ & - & $1 \varepsilon$ & $\overline{-}$ & 0 & 9 & الإكو ادور \\
\hline $\mathrm{v}$ & $\mathrm{V}$ & $r$ & 11 & $\varepsilon$ & 1. & 1 & $\pi$ & شيلي \\
\hline $1 \varepsilon$ & $\overline{--}$ & 9 & 0 & $\mathrm{v}$ & $\mathrm{V}$ & 9 & 0 & الأرجنتين \\
\hline $1 \varepsilon$ & $\overline{-}$ & 9 & 0 & $1 \varepsilon$ & $\overline{-}$ & $1 \varepsilon$ & - & تايلاند \\
\hline $1 \varepsilon$ & -- & $1 \varepsilon$ & -- & $1 \varepsilon$ & -- & 14 & 1 & كوريا \\
\hline $1 \varepsilon$ & - & 11 & $r$ & - & $1 \varepsilon$ & $\pi$ & $r$ & إندونيسيا \\
\hline $1 \varepsilon$ & $\overline{-}$ & 9 & 0 & 7 & $\Lambda$ & 7 & $\Lambda$ & الفلبين \\
\hline-- & $1 \varepsilon$ & $r$ & Tr & 0 & 9 & $1 \varepsilon$ & -- & ماليزيا \\
\hline $1 \varepsilon$ & -- & $1 \varepsilon$ & -- & $1 \varepsilon$ & $-\cdot$ & $\Lambda$ & 7 & تركيا \\
\hline $1 \varepsilon$ & - & $1 \varepsilon$ & - & 1. & $\varepsilon$ & $1 \varepsilon$ & - & روسيا \\
\hline & & & & & & 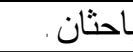 & كي إعداد & المص - المص \\
\hline
\end{tabular}

تحليل الاحدار الخطي المتعدد

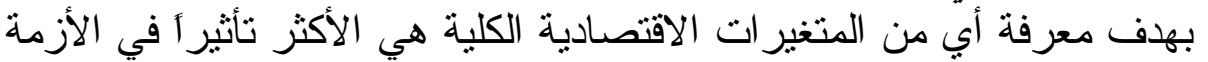

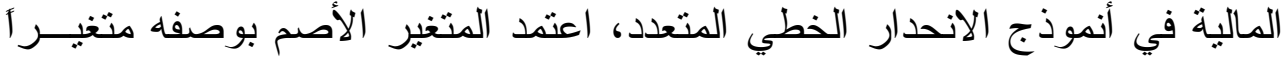

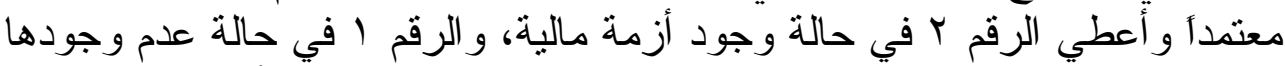

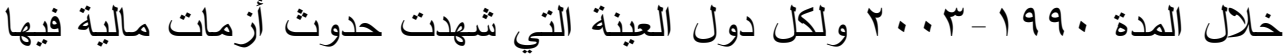
وفي سنو ات مختلفة وفي ظروف مادو منباينة.

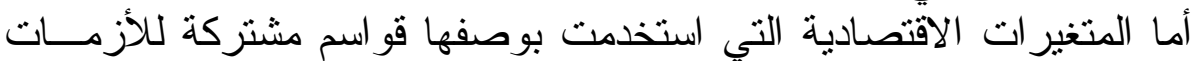

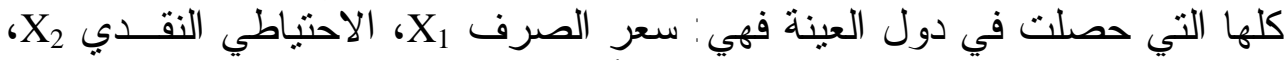

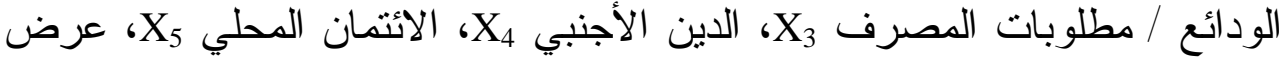

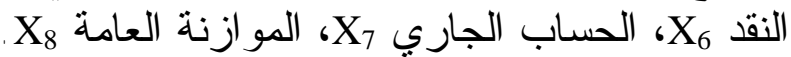


وتم توحيد بيانات المتغير ات الاقتصادية الكلية بعملة و احدة (الدو لار ) بدلا من

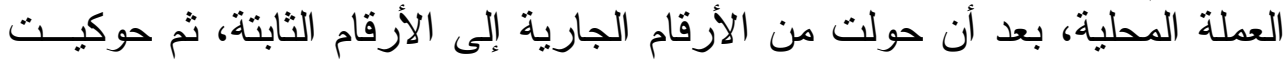

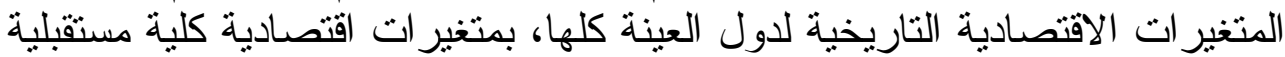

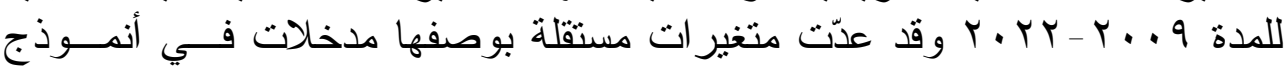

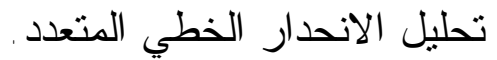

و هذا يعني وجود مرحلتين لتحليل الانحدار الخطي المتعدد لدول العينة العينة كلها:

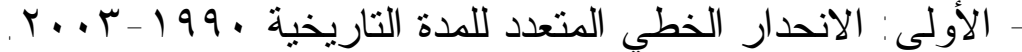

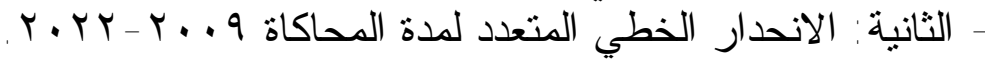

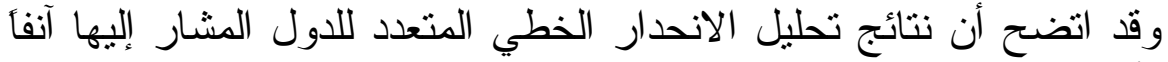

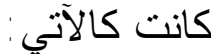

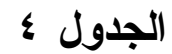

تحليل الاتحدار الخطي المتعدد لاول العينة للمدة ـ 199 -ب ...

\begin{tabular}{|c|c|c|c|}
\hline$\overline{\mathbf{R}^{2}}$ & $\mathbf{F}$ & المعادلة & الاولة \\
\hline 0.67 & 4.648 & $\begin{array}{l}\mathrm{Y}=0.775+0.001 \mathrm{X}_{1}-0.0001 \mathrm{X}_{2}+0.38 \mathrm{X}_{6}-5.93 \mathrm{E}-05 \mathrm{X}_{7} \\
\mathrm{t}=(2.772)^{*}(3.603)^{*}(-3.585)^{*}(3.121)^{*}(-2.561) *\end{array}$ & الأرجنتين \\
\hline 0.70 & 29.161 & $\begin{array}{l}\mathrm{Y}=1.228-3.12 \mathrm{e}-05 \mathrm{X}_{8} \\
\mathrm{t}=(21.629) *(-5.400) *\end{array}$ & المكسيك \\
\hline 0.93 & 21.131 & 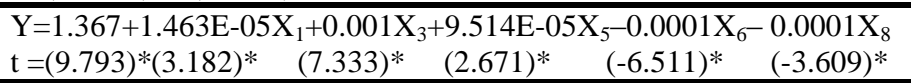 & الإكو ادور \\
\hline 0.48 & 0.582 & 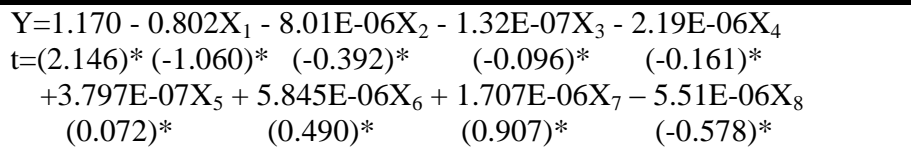 & البر ازيـــلـل \\
\hline 0.96 & 26.010 & 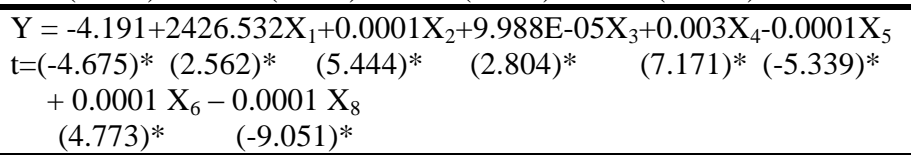 & شيلي \\
\hline 0.73 & 9.216 & $\begin{array}{l}\mathrm{Y}=0.534+0.024 \mathrm{X}_{1}-0.0001 \mathrm{X}_{2}+8.696 \mathrm{E}-05 \mathrm{X}_{3} \\
\mathrm{t}=(2.423)^{*}(2.549)^{*}(-3.801)^{*} \quad(5.088)^{*}\end{array}$ & الفلبين \\
\hline 0.88 & 17.187 & $\begin{array}{l}\mathrm{Y}=0.568+0.0001 \mathrm{X}_{3}+6.402 \mathrm{E}-05 \mathrm{X}_{4}-8.82 \mathrm{E}-06 \mathrm{X}_{5}+5.748 \mathrm{E}-05 \mathrm{X}_{8} \\
\mathrm{t}=(2.462)^{*} \\
\end{array}$ & إندونيسيا \\
\hline 0.90 & 21.176 & 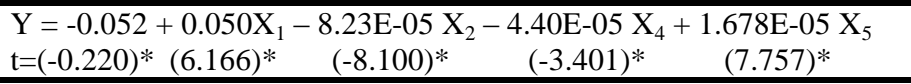 & تايلاند \\
\hline 0.98 & 125.445 & $\begin{array}{l}\mathrm{Y}=1.104+7.203 \mathrm{E}-05 \mathrm{X}_{4}+1.843 \mathrm{E}-06 \mathrm{X}_{5}-3.79 \mathrm{E}-06 \mathrm{X}_{6}-6.09 \mathrm{E}-06 \mathrm{X}_{8} \\
\mathrm{t}=(20.173)^{*}(21.615)^{*} \\
\end{array}$ & كوريــا \\
\hline 0.91 & 18.270 & 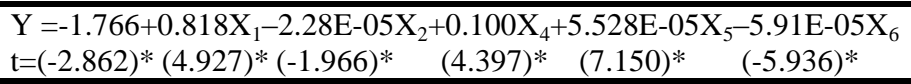 & ماليزيا \\
\hline 0.93 & 33.290 & 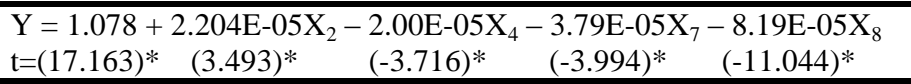 & تركــيا \\
\hline 0.82 & 4.367 & 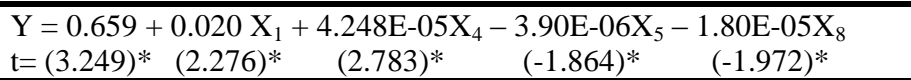 & נر \\
\hline
\end{tabular}


الدكتور الجميل وداؤد [•rY]

\begin{tabular}{|c|c|c|c|}
\hline \multicolumn{4}{|c|}{ 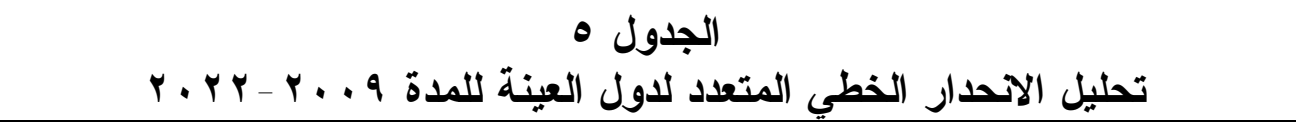 } \\
\hline$\overline{\mathbf{R}^{2}}$ & $\mathbf{F}$ & المعادلة & الاولة \\
\hline 0.728 & 6.033 & $\begin{array}{l}\mathrm{Y}=1.849-0.0001 \mathrm{X}_{1}-1.56 \mathrm{E}-05 \mathrm{X}_{3}-0.004 \mathrm{X}_{6}-5.95 \mathrm{E}- \\
06 \mathrm{X}_{8} \\
\mathrm{t}=(10.146) *(-3.495) * \quad(-2.082)^{*} \quad(-2.762)^{*}(-2.138)^{*}\end{array}$ & الأرجنتين \\
\hline 0.31 & 5.41 & $\begin{array}{l}\mathrm{Y}=0.385+0.066 \mathrm{X}_{1} \\
\mathrm{t}=(1.704)^{*}(2.326)^{*}\end{array}$ & المكسيك \\
\hline 0.34 & 6.201 & $\begin{array}{l}\mathrm{Y}=0.628+0.001 \mathrm{X}_{3} \\
\mathrm{t}=(2.258)^{*}(2.490)^{*}\end{array}$ & الإكو ادور \\
\hline 0.58 & 0.882 & 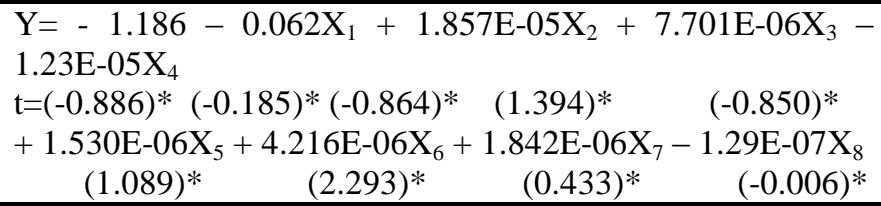 & البر ازيـــلـ \\
\hline 0.97 & 81.867 & 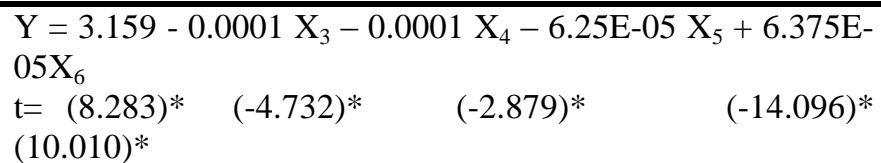 & شيلي \\
\hline 0.56 & 0.79 & $\begin{array}{l}\mathrm{Y}=3.514-0.023 \mathrm{X}_{1}+0.0001 \mathrm{X}_{2}-0.0001 \mathrm{X}_{3}-0.0001 \mathrm{X}_{4}+9.104 \mathrm{E}- \\
06 \mathrm{X}_{5} \\
\mathrm{t}=(1.449)^{*}(-1.125) *(1.363)^{*}(-1.190)^{*}(-0.472)^{*} \\
\quad+(0.496)^{*} \\
\quad+292 \mathrm{E}-06 \mathrm{X}_{6}-8.61 \mathrm{E}-05 \mathrm{X}_{7}-3.00 \mathrm{E}-05 \mathrm{X}_{8} \\
\quad(0.297)^{*} \quad(-0.869)^{*} \quad(-0.152)^{*}\end{array}$ & الفلبين \\
\hline 0.41 & 8.466 & $\begin{array}{l}\mathrm{Y}=0.663+5.478 \mathrm{E}-06 \mathrm{X}_{6} \\
\mathrm{t}=(1.898)^{*} \quad(2.910)^{*}\end{array}$ & إندونيسيا \\
\hline 0.51 & 12.500 & $\begin{array}{l}\mathrm{Y}=1.185+1.467 \mathrm{E}-05 \mathrm{X}_{7} \\
\mathrm{t}=(9.179)^{*}(3.536)^{*}\end{array}$ & تايلاند \\
\hline 0.94 & 40.973 & $\begin{array}{l}\mathrm{Y}=1.594+0.0001 \mathrm{X}_{1}+3.988 \mathrm{E}-05 \mathrm{X}_{4}-3.74 \mathrm{E}-06 \mathrm{X}_{5}+ \\
3.724 \mathrm{E}-06 \mathrm{X}_{6} \\
\mathrm{t}=(7.642)^{*}(4.391) *(2.277)^{*} \quad(-10.103) * \\
\end{array}$ & كوريـــا \\
\hline 0.43 & 0.473 & $\begin{array}{ll}\mathrm{Y}= & -2.154+0.463 \mathrm{X}_{1}-2.27 \mathrm{E}-05 \mathrm{X}_{2}-5.53 \mathrm{E}- \\
05 \mathrm{X}_{3}+0.108 \mathrm{X}_{4}+1.678 \mathrm{E}-05 \mathrm{X}_{5} & \\
\mathrm{t}=(-0.358) *(0.336) *(-0.232) *(0.214)^{*}(0.809)^{*} & (0.829)^{*} \\
& +1.703 \mathrm{E}-05 \mathrm{X}_{6}+3.746 \mathrm{E}-05 \mathrm{X}_{7}-7.47 \mathrm{E}-05 \mathrm{X}_{8} \\
& (0.709)^{*} \quad(0.862)^{*} \quad(-0.440)^{*}\end{array}$ & ماليزيا \\
\hline 0.42 & 3.978 & $\begin{array}{l}\mathrm{Y}=1.688+8.361 \mathrm{E}-06 \mathrm{X}_{5}-1.25 \mathrm{E}-05 \mathrm{X}_{6} \\
\mathrm{t}=(4.026)^{*}(2.196)^{*} \\
\end{array}$ & تركـيا \\
\hline 0.29 & 2.315 & $\begin{array}{l}\mathrm{Y}=1.072+5.974 \mathrm{E}-05 \mathrm{X}_{3}-2.29 \mathrm{E}-05 \mathrm{X}_{7} \\
\mathrm{t}=(5.146)^{*} \\
(2.112)^{*}\end{array}$ & روسيا \\
\hline
\end{tabular}




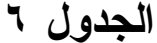

القواسم المشتركة للمتغيرات الاقتصادية الكلية لاول الأزمة المالية

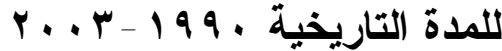

\begin{tabular}{|c|c|c|c|c|c|c|c|c|}
\hline الاحتياطي & الودائع/ مطربوبات & العوازنة & الجاري & الأجنبي & الالمحتم & عرض النقا & سلصفت & دول الأزمة \\
\hline \multirow[t]{3}{*}{$x$} & & & $\bar{x}$ & & & $\bar{x}$ & $\bar{x}$ & الأرجنتين \\
\hline & & & & & & & & البرازيل \\
\hline & $\bar{x}$ & $\bar{x}$ & & & $\bar{x}$ & $\bar{x}$ & $\bar{x}$ & الإكو ادور \\
\hline \multirow[t]{2}{*}{$x$} & $\bar{x}$ & $\bar{x}$ & & $\bar{x}$ & $\bar{x}$ & $\bar{x}$ & $\bar{x}$ & شيلى \\
\hline & & $\bar{x}$ & & & & & & المكسيك \\
\hline $\bar{x}$ & & & & $\bar{x}$ & $\bar{x}$ & & $\bar{x}$ & تابإلاند \\
\hline $\bar{x}$ & & & & $\bar{x}$ & $\bar{x}$ & $\bar{x}$ & $\bar{x}$ & ماليزيا \\
\hline \multirow[t]{3}{*}{$\bar{x}$} & $\bar{x}$ & & & & & & $\bar{x}$ & الفلبين \\
\hline & $\bar{x}$ & $\bar{x}$ & & $\bar{x}$ & $\bar{x}$ & & & إندونيسيا \\
\hline & & $\bar{x}$ & & $\bar{x}$ & $\bar{x}$ & $\bar{x}$ & & كوريا \\
\hline \multirow[t]{2}{*}{$x$} & & $\bar{x}$ & $\bar{x}$ & $\bar{x}$ & & & & تركيا \\
\hline & & $\bar{x}$ & & $\bar{x}$ & $\bar{x}$ & & $\bar{x}$ & روسيا \\
\hline
\end{tabular}

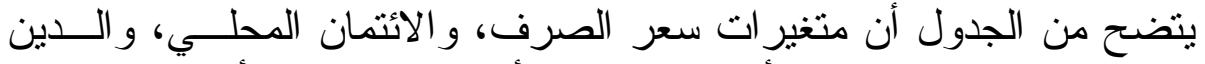

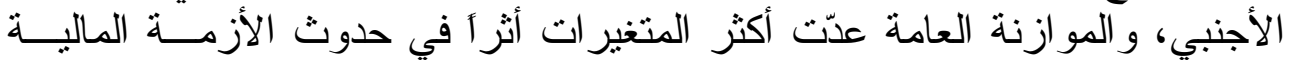

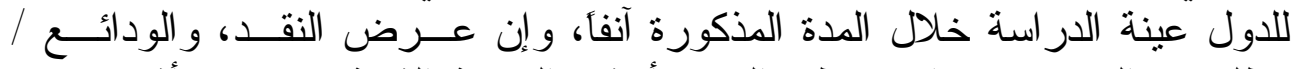

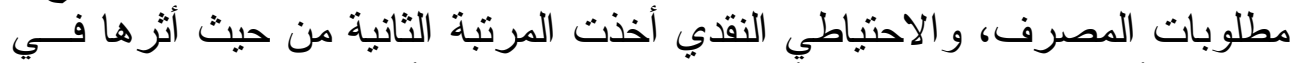

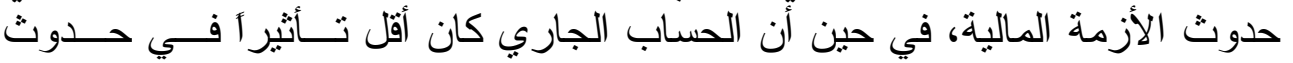

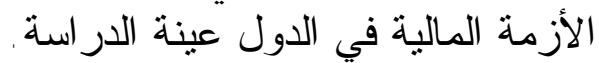

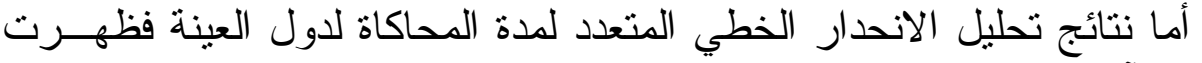

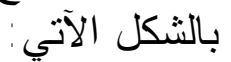

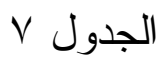

القواسم المشتركة للمتغيرات الاقتصادية الكلية لاول الأزمة المالية

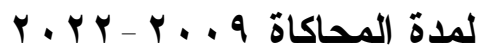

\begin{tabular}{|c|c|c|c|c|c|c|c|c|}
\hline الاحتياطي & المطوباتت & العامة & الجاري & الأجنبي & المحتي & عزض النق & سلصف & دلدل الأزمة \\
\hline & $\bar{x}$ & $\bar{x}$ & $\bar{x}$ & & & $\bar{x}$ & $x$ & الأرجنتين \\
\hline & & & & & & & & البر ازيل \\
\hline & $\bar{x}$ & & & & & & & الإكو ادور \\
\hline & $\bar{x}$ & & & $x$ & $\bar{x}$ & $x$ & & شيد \\
\hline
\end{tabular}




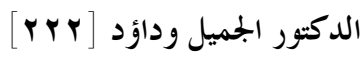

\begin{tabular}{|c|c|c|c|c|c|c|c|c|}
\hline الاحتباطي & المطروبات & العامة & الجاري & الأجنبي & المحلي & النقا & الصرف & دالمالالية \\
\hline & & & & & & & $\bar{x}$ & المكسيك \\
\hline & & & $\bar{x}$ & & & & & تايلاند \\
\hline & & & & & & & & ماليزيا \\
\hline & & & & & & & & الفلبين \\
\hline & & & & & & $x$ & & إندونيسيا \\
\hline & & & & $\bar{x}$ & $\bar{x}$ & $\bar{x}$ & $x$ & كوريا \\
\hline & & & & & $\bar{x}$ & $x$ & & تركيا \\
\hline & & & $x$ & & & & & روسيا \\
\hline
\end{tabular}

المصدر: من إعداد الباحثان.

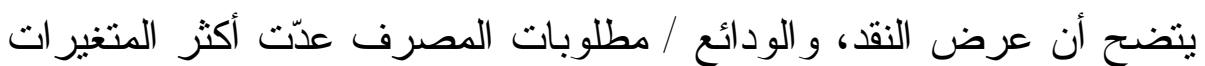

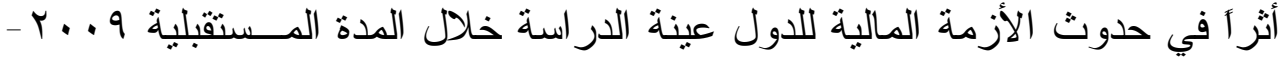

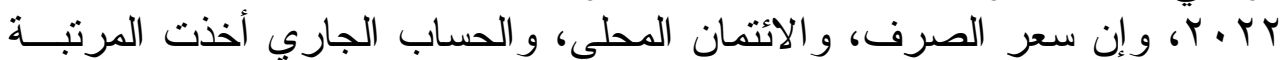

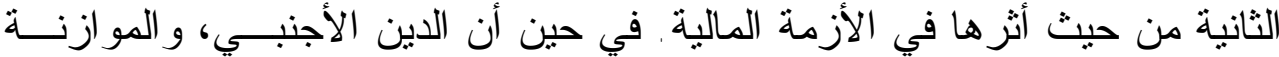

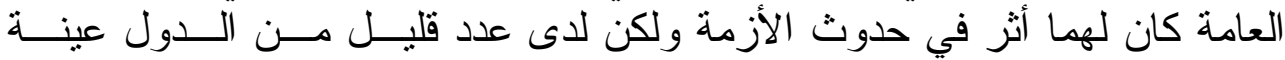

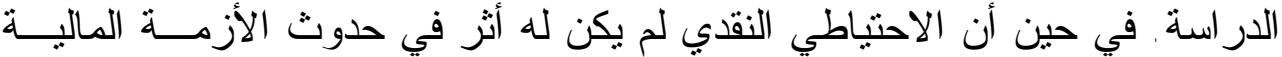

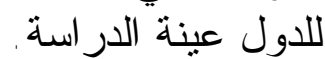

الاستنتاجات الات الاتر

خلصت الدراسة إلى عدد من الاستتناجات كان أههها:

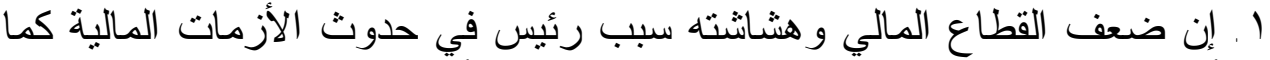

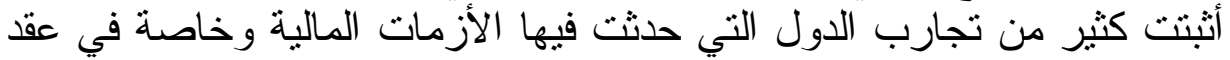

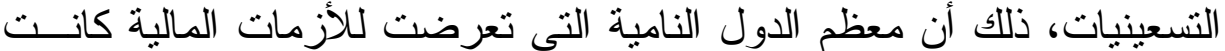

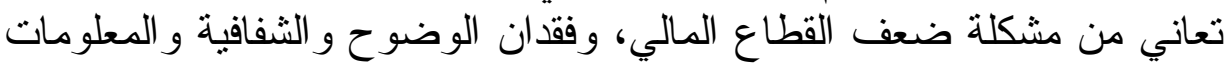
الو اضحة و الكاملة عن النظام المالي . الكئي

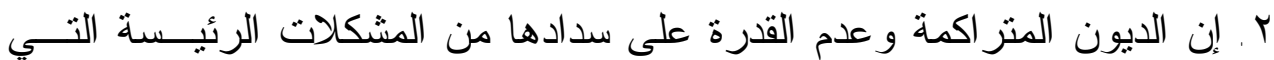

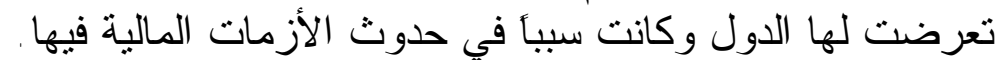

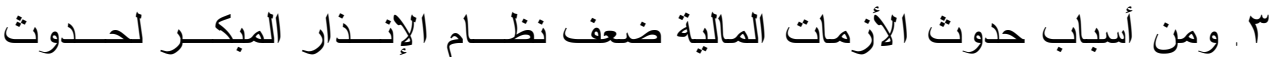

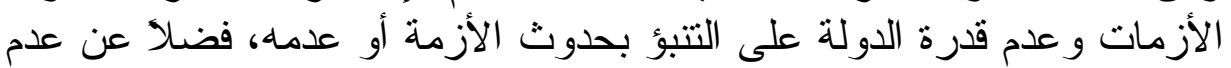

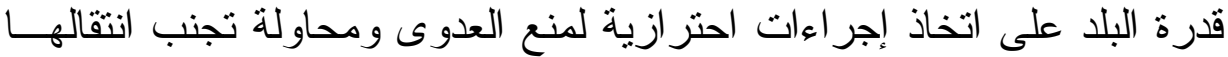

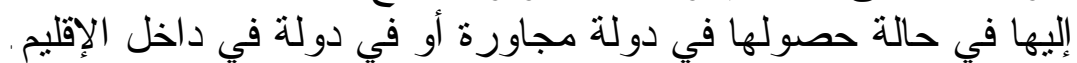

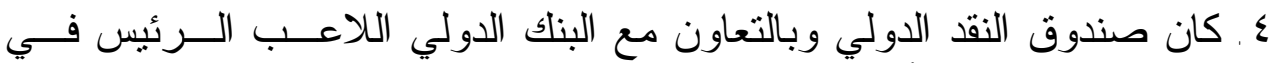

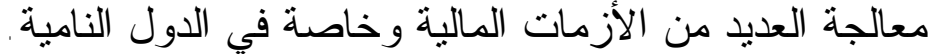

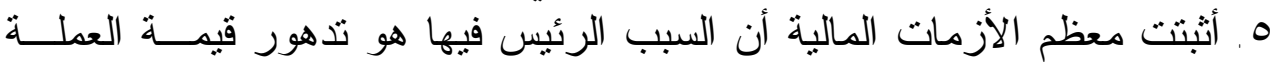

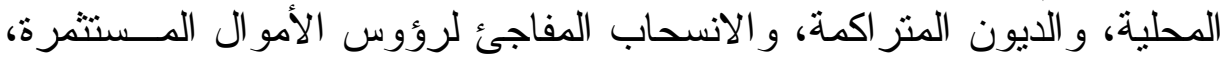


و الاستخدام غير المدروس للسياسات المالية التحررية وخاصــة فــي الــدول

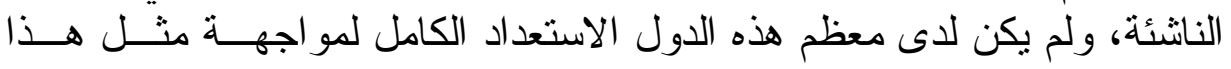
التحرر و افتقار ها إلى تحديد التسلسل التهلئل الملائم.

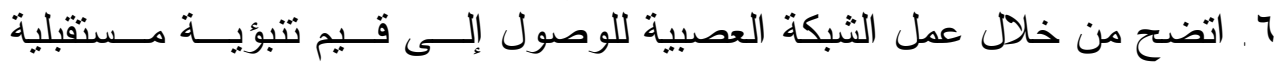

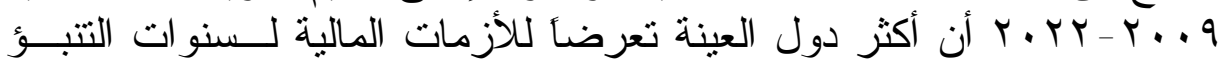

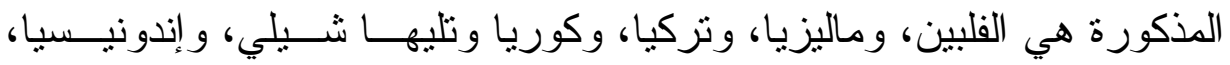

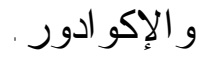

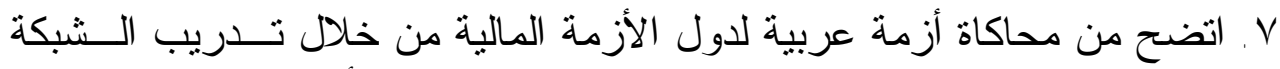

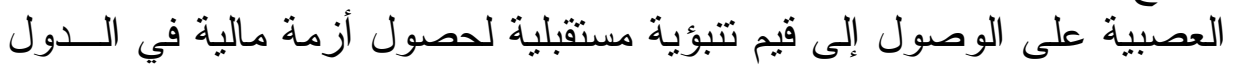

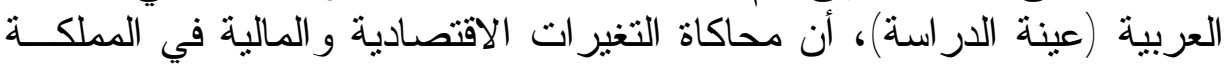

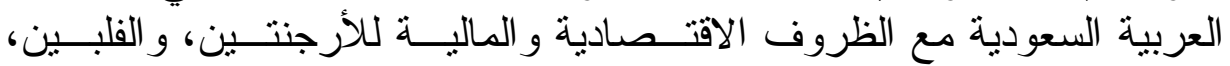

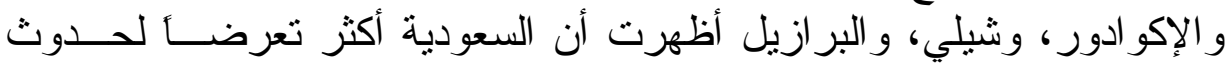

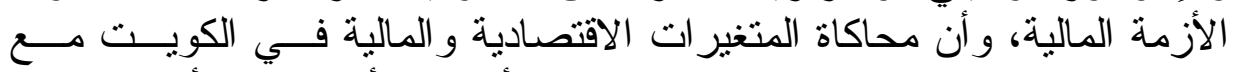

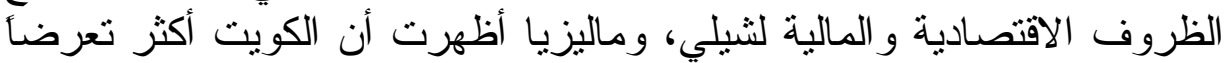

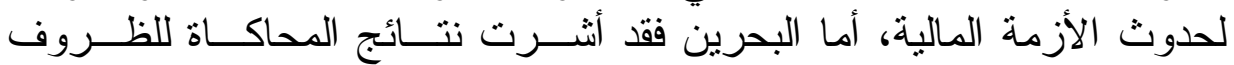

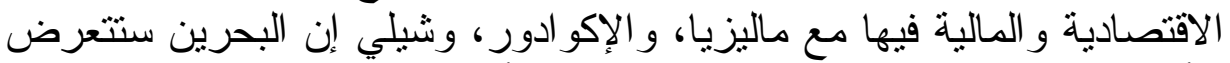

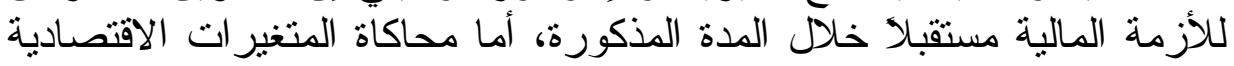

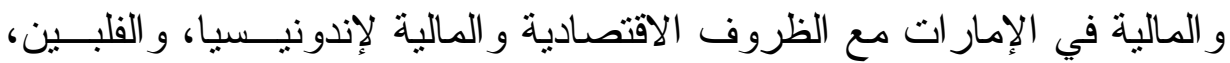

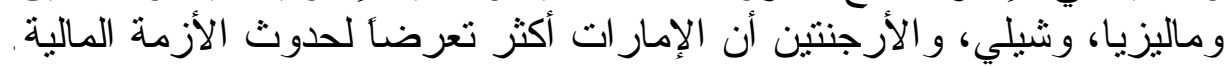

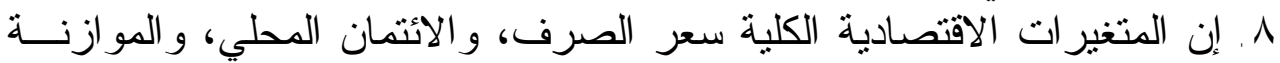

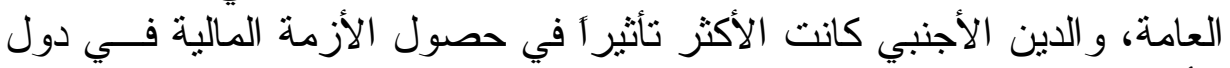

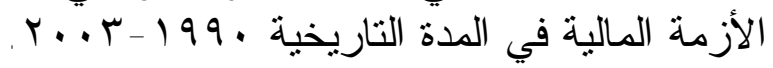

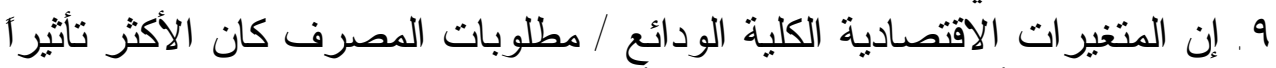

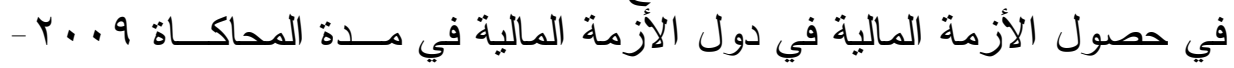
r. r r

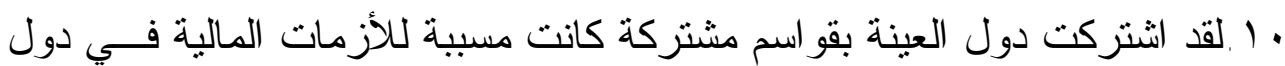

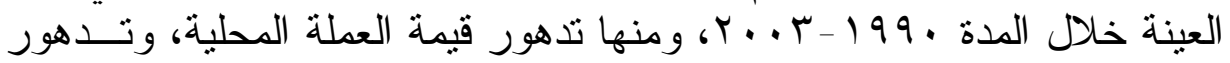

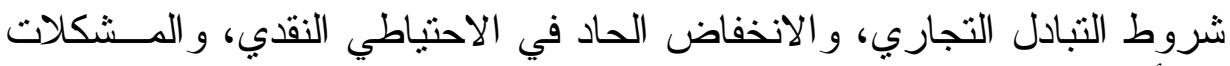

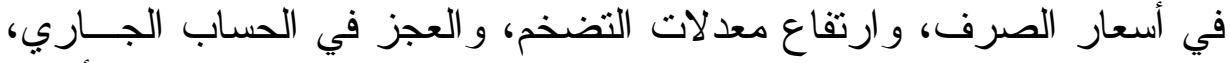

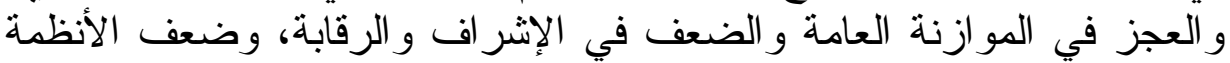
المالية في دول عينة الدر اسة. 


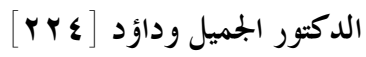

$$
\text { توصلت الدر اسة إلى عدد من التوصيات أهمها: }
$$

التوصيات

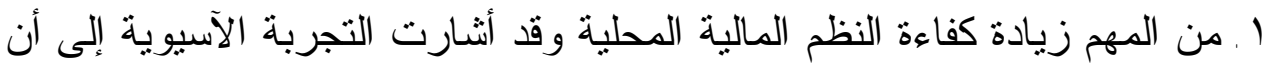

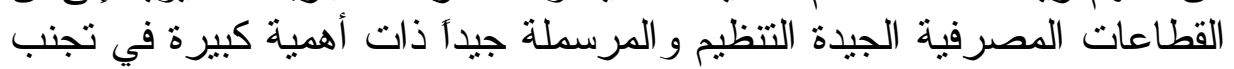

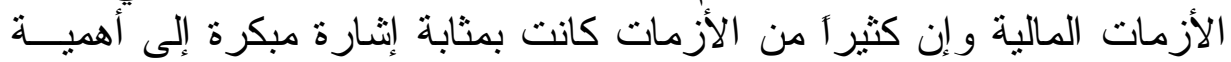

وجود نظم مالبة قوية.

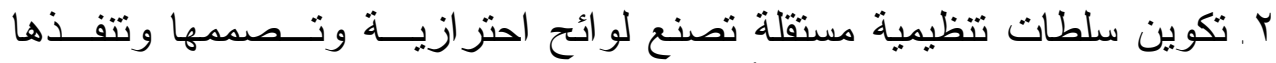

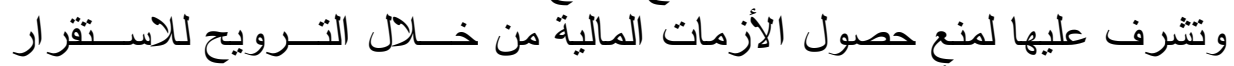

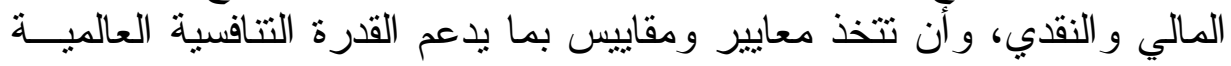
لكل دولة. r. تطوير الأسواق المحلية للسندات التي تؤدي إلى وساطة مالية أكثر كفاءة بــين

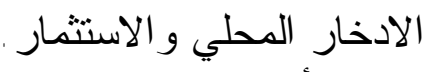

ع . إعطاء أهمية كبيرة لتطوير أسواق الأسهر حتى تجذب تدفقات استثمارية وتقلل

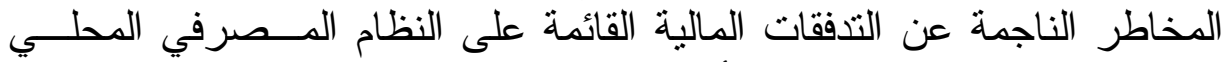
و عن الائتمان المحلي القصير الأجل. 0. أن تكون هناك إدارة جيدة للايون المحلية والخارجية تخفف من وصول الدولة إلى المديونية الخارجية.

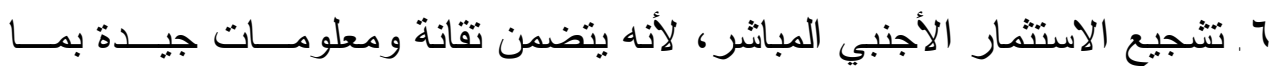

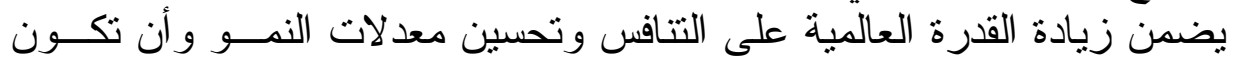
هناك قو انين خاصة بادة بالمستثمر الأجنبي.

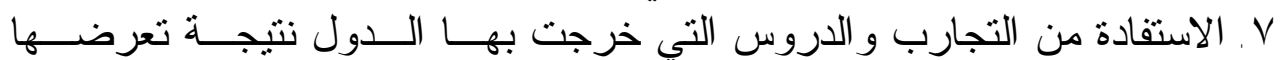

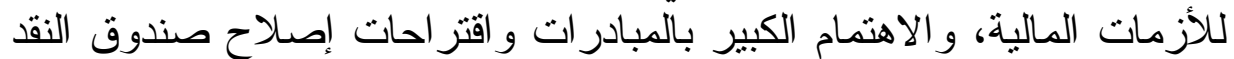

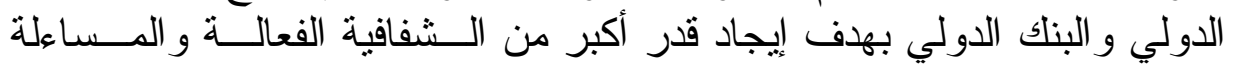

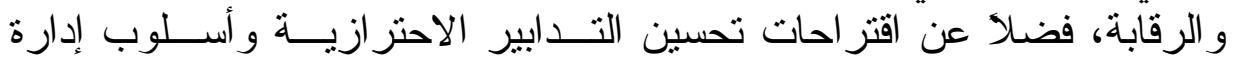

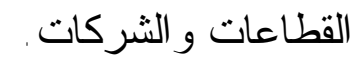

A . تخصيص أمو ال كبيرة للتمويل في المؤسسات المالية العالمية وبنـــوك التتميـــة

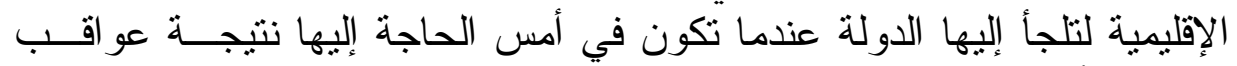

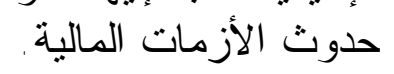

9 ـ الالتز ام بجانب الحرص و الحذر من تدفقات كبيرة لرؤوس الأمـــو ال، وجعلهــــا

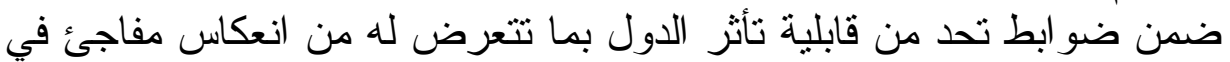

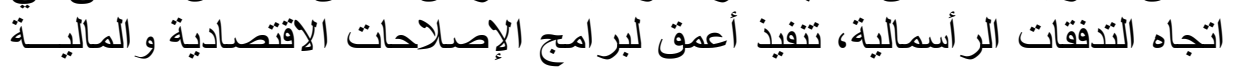

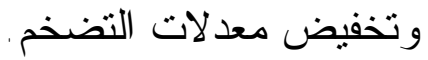

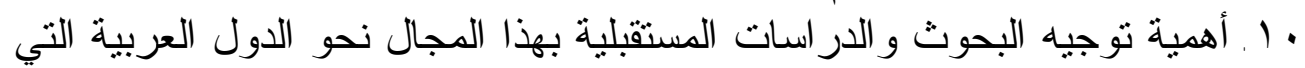

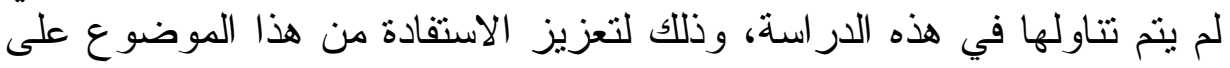
الصعيد العربي. 
1. Crafts Nicholas, 1998, "Asian's Miracle: The Think It's All Over-it Need not be Yet", School of Economics, London.

2. Diamond Douglas W. and Dyobrig, Philip H., 1993, "Banks Runs, Deposit Insurance and Liquidity", The Journal of Political Economy, Vol. 93, No. 3.

3. Enrica Detragiache \& Antonio Spilimbergo, 2001, "Crisis and Liquidity: Evidence and Interpretation", International Monetary Fund, Working Papers WP/01/2.

4. Faramarz Valafar, Ersoy Okank, 2004, A Parallel Implementation of Backpropagation Neural Network on Maspar. Mp-1, School of Electrical Engineering, Purdue University, W. Lafayette, IN 47907.

5. Franklin Allen \& Douglas Gale, 2000, Bubbles and Crises, The Economic Journal 110, Published by Blackwell Publishers.

6. Frederic S. Mishkin, 2004, Can Inflation Targeting Work in Emerging Market Countries, Festechift in Honor of Guillermo A. Calvo, April, IMF.

7. G. Merlo, P. Britos, B. Rossi, \& Garcia Martinez, 2004, Neurl Network Applied to Automatic Estimation of Networks Performance, University of Buenos Aires, Madero 399. 11061 Bueons Aires, Argentina.

8. Gionnetti Mariassunta, 2004, "Financial Crisis and Incomplete Informations, Stockholm School Economics.

9. Graciela Kaminsky \& Carmen Reinhart, 1995, "The Twin Crisis: The Cause of Banking and Balance of Payment Problems", International Monetary Fund.

10.Guillermo Calvo \& Morris Goldstein, 1996, "Private Capital Flows to Emerging Markets after the Mexican Crisis, Institute for International Economics, Washington.

11.H. G. Francisco, Philip G. Leite Ferreira and Others, 2004, Can the Distributional Impacts of Macroeconomic Shocks be Predicted, World Bank Policy, Working Paper 3303.

12.H. Lee Chung, 2004, "Financial Liberalization and Economic Crisis in Asia", University of Hawaii at Manoa, East-West Center and European Institute of Japanese Studies, Stockholm School of Economy.

13.Hok K. Pyo, 2002, On Currency Crisis-A Cause of South Korea 20th March.

14.Hyman Minsky, 1995, Financial Factors in the Economics of Capitalism, Journal of Financial Services Research.

15.Hyman Minsky, 1995, Longer Waves in Financial Relations: Financial Factors more Severe depression II, Journal of Economic Issues, 29, March.

16.IMF, 1995, "International Capital Market World Economic and Financial Surveys, International Monetary Fund, Washington.

17.IMF, 1995, "International Capital Markets", International Monetary Fund, Washington.

18.International Monetary Fund Survey, 1998, No. 1, January 12.

19.Jeffrey Frankela \& Andrew K. Ros, 1996, "Currency Crashes in Emerging Markets: An Empirical Treatment", Journal of International Economic, Vol. 41, November.

20.Jill Solomon; Aris Solomon \& Chang-Young, 2002, The Revolving Role of Institutional Investors in South Korea Corporate Governance: Some Empirical Evidence, Vol. 10, No. 3, Oxford, U. K.

21.John C. Dawson, 2004, "The Asian Crisis and Flow-of-Funds Analysis, Review of Income and Wealth", Series 50, No. 2, June.

22.Jos'e De Gregorio \& Rodeigo O. Valder's, 2001, “Transmission: Evidence from the Debt, Tequila and Asian Flu Crises, The World Bank Economic Review, Vol. 15, No. 2289-314.

23.K. Nanto Dick, 1998, "CRS Report of Congress, the 1997-1998 Asian Financial Crisis", February. 


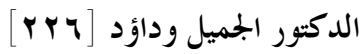

24.Kaminskey Craciela, 1998, Leading indicators of Currency Crisises, International Monetary Fund, Staff Papers, March.

25.K-Kiang M. Tam 1992, "Managerial Applications of Neural Networks: The Case of Bank Failure", Management Science, 38, 7.

26.Linda Lim, 1999, A Overview of Asian Financial Crisis, Journal of Asian Business, Vol. 15, No. 1.

27.M. Giannetti, 2002, "Financial Crisis and Incomplete Information, Stockholm School of Economic, Mimeo.

28.M. Giannetti, 2002, "On the Causes of Over-lending are Guarantees on Deposit the Culprit”, Stockholm School of Economic, Mimeo.

29.M. Giannetti, 2002, Bank-Firm Relationships and Contagious Banking Crisis, Journal of Money, Credit and Banking.

30.Manmohan S. Kumar, 2001, "Global Financial Crisis", International Monetary Fund, Working Paper, WP/00/105.

31.Michael Bordo and Barry Eichengreen, 1999, "Is Our Current International Economic Environment Unusually Crisis Prone, World Bank.

32.Michel Camdessus, 1998, "The Asian Financial Crisis and the Opportunities of Globalization", International Monetary Fund.

33. Michel Camdessus, 1999, "The Financial Crises in the Developing Markets", IMF Survey Vol. 28, No. 4, February.

34.Morris Goldstein, 1999, "The Asian Financial Crisis Causes and Systemic Implications", Washington, Institute for International Economics Growth and Change, Vol. 30.

35.Neil Karunaratne, 2002, Globalization, Crisis Contangion and the Reform of the International Financial Architecture, Discussion Paper, No. 300, ISSN 1033-4661, Australia.

36.Paolo Pesenti \& Cedric Tille, 2000, The Economics of Currency Crisis and Contanion: An Introduction, FRBNY, Economic Policy Review, September.

37.Pastor Genzalo \& Tatinana Damjanovic, 2001, "The Russian Financial Crisis and Its Consequences", Working Paper, WP/01/169, October.

38.Patrick Hanohan, 1996, "Financial System Failures in developing Countries", International Monetary Fund, Working Paper.

39.Paul Collier and Jam Willem Gunning, 2000, The IMF's Role in Structural Adjustment, The Economic Journal 109, Published by Blackwell Publishers.

40.Rafael Laporla, \& Andrei Shleifer, 2000, Government Ownership of Banks, NBER, Working Paper Series, Working Paper 7620.

41.Robert Flood and Nancy Marion, 1998, Perspectives on the Recent Currency Crisis Literature, NBER Working Paper 6380, January.

42.S. Edwards, 1997, Bank and Macroeconomic Disturbances Under Predetermined Exchange Rates, Journal of Monetary Economics, Vol. 40.

43. Stephen Greville, 2004, "The IMF and the Indonesian Crisis, IMF, Independent Evaluation Office Background Paper, BP/04/3.

44.Susan K. Schroeder, 2002, A Minskian Analysis of Financial Crisis in developing Countries, New School University and University of Bremen, Working Paper 2002-09, New York.

45.Taimur Baigan Lian, 1999, "Financial Markets Contagion in the Asian Crisis, International Monetary Fund, Staff Papers, Vol. 46, No. 2, June.

46. Yiping Huang \& Yongzheng Yang, 1999, "China's Financial Fragility and Policy Responses", Columbia University, New York, The Australian University (Blackwell site).

47. Yoon Cho, Je \& Khatkate, Deena, 1989, "Lessons of Financial Liberalization in Asia: A Comparative Study", World Bank Discussion Papers, World Band, Washington.

48. Yoshitomi Masaru \& Kenichi Ohno, 1999, "Capital Account Crisis and Credit Contraction, ADB, Institute Working Paper Series, No. 2. 